\title{
CUESTIONES CONTROVERTIDAS EN LA \\ APLICABILIDAD DE LAS CAUSAS DE JUSTIFICACIÓN \\ A LOS DELITOS IMPRUDENTES*
}

CONTROVERSIAL ISSUES ABOUT CLAIMS OF

JUSTIFICATION IN NEGLIGENT CRIMES

QUESTIONS CONTROVERSÉES DE

L'APPLICABILITÉ DES MOTIFS DE JUSTIFICATION

POUR LES DELITS COUPABLES

\section{Luciana de Oliveira Monteiro**}

\begin{abstract}
Resumen
El presente artículo trata de cuestiones controvertidas en la aplicación de las causas de justificación, que afectan a la relación existente entre tipicidad y antijuridicidad, y de esta con la culpabilidad, en el ámbito de los delitos imprudentes. Esas cuestiones se revelan todavía más problemáticas cuando a ellas añadimos consideraciones acerca del error en las causas de justificación y su repercusión en el ámbito de la punibilidad de los delitos imprudentes. Todos esos aspectos serán discutidos con el objetivo de manifestar nuestra opinión al respecto, polemizando las posturas de los diferentes sectores de la doctrina.
\end{abstract}

\begin{abstract}
The present article deals with controversial issues, both concerning the application of claims of justification and affecting the relationship between typification of a crime and wrongdoing, as well as between the latter and culpability, in the sphere of negligent crimes. The said issues appear even more troublesome when considerations on error regarding claims of justification and its implications for the criminality of negligent crimes are taken into account. All these points will be discussed, debating the positions of the different sectors of doctrine, with the aim of expressing our views on the matter.
\end{abstract}

\footnotetext{
* El artículo fue recepcionado el 15 de junio de 2011, y aprobado para su publicación el 24 de noviembre de 2011.

** Abogada. Licenciada en Derecho por la Universidad Federal de Bahia. Doctora en Derecho por la Universidad Pablo de Olavide de Sevilla. Profesora de la Facultad de Derecho de la Universidad Federal de Bahia, Departamento de Derecho Público, área de Derecho Penal.
} 


\section{RÉSUMÉ}

Cet article traite des questions controversées dans la mise en œuvre des causes de justification, qui affectent la relation entre la typicité, l'antijuridicité et la culpabilité en les delits coupables. Ces questions sont révélés encore plus problématique quand il ajoute des considérations sur l'erreur dans les motifs de justification et de leur impact sur la punition des delits coupables. Tous ces aspects seront discutés avec le but d'exprimer notre opinion sur la question, arguant des positions des différents secteurs de la doctrine.

Palabras Claves:

Delito imprudente - Causas de justificación - Error

KeY Words:

Negligent crimes - Claims of justification - Error

Mots Clé:

Delits coupables - Motifs de justification - Erreur 


\section{INTRODUCCIÓN}

El progresivo interés por parte de la doctrina española en el estudio particularizado de la imprudencia, a lo largo de los últimos 20 años, ha suscitado una importante discusión en torno a cuestiones específicas de la dogmática penal que habían sido inicialmente planteadas con referencia a los delitos dolosos.

Algunas de esas cuestiones, que serán aquí mencionadas como tema de debate, giran en torno a la aplicabilidad de las causas de justificación a los delitos imprudentes y se refieren tanto a la indagación de si aquellas cumplen la misma función valorativa para afirmar o negar la antijuridicidad de la conducta típica imprudente, como a la problemática más específica del desconocimiento de los elementos objetivos de una causa de justificación (también referido en la doctrina como error inverso sobre la concurrencia en el hecho de los presupuestos objetivos de una causa de justificación), y de la suposición errónea de los presupuestos objetivos de una causa de justificación (error sobre la concurrencia en el hecho de los presupuestos objetivos de una causa de justificación).

El abordaje de estos temas se justifica en la medida en que no son nada desdeñables las diferencias entre las propuestas formuladas en la doctrina, que aplicadas a un marco jurídico concreto, en este caso al Código Penal español de 1995, repercute, en cuanto a los efectos que produce, en la caracterización del injusto imprudente y su punibilidad. En efecto, la controvertida discusión acerca de los elementos característicos del injusto imprudente, de si se debe, o no, concebir el delito imprudente de manera globalmente diversa al doloso, repercute significativamente en la conformación de las categorías sistemáticas del delito. Y esa problemática se ve todavía más agravada cuando a ella añadimos la discusión sobre el error en las causas de justificación, pues, dependiendo de la concepción de delito de que se parta, se alcanzarán conclusiones distintas acerca de la naturaleza jurídica del error, su ubicación sistemática entre las categorías del delito, los criterios de valoración de la vencibilidad o invencibilidad de las especies de error, su eficacia atenuante o excluyente de la responsabilidad penal, etc.

Ciertamente no tenemos aquí la pretensión de abordar todos estos temas, que, por su dimensión y envergadura, demandan un análisis extendido que no se adecuan a los límites de este trabajo. Nuestro objetivo se circunscribe, más bien, a la problematización de la aplicación de las causas de justificación desde la perspectiva de los delitos imprudentes, es decir, a partir de un entendimiento concreto acerca del injusto imprudente, cuestión que analizamos a continuación. 


\section{LA CONCEPCIÓN PERSONAL DEL INJUSTO Y LA CONCEPCIÓN TRI- PARTITA DEL DELITO IMPRUDENTE}

La responsabilidad por imprudencia implica un juicio de contrariedad a una determinada norma de cuidado y se basa en un reproche por no haber sido (o no haber sido suficientemente) cuidadoso, diligente o precavido en la realización de una conducta peligrosa ${ }^{1}$.

Con este punto de partida, emana una amplia divergencia con respecto a la concepción de injusto a la hora de identificar el contenido y los elementos que integran esa categoría en el delito imprudente. Sin la pretensión de reproducir aquí los términos de ese debate, partimos de la base de que, en la caracterización de una conducta como imprudente, lo más adecuado es adoptar una concepción personal del injusto y asumir la existencia de un tipo objetivo-subjetivo en los delitos imprudentes, asumiendo la consecuente necesidad de identificar la medida de cuidado individualmente exigible en el momento de la acción.

Desde esa perspectiva, entendemos que el deber de cuidado se relaciona con la concreta situación de peligro que genera la conducta y debe corresponder a la medida de cuidado necesaria para evitar que el riesgo supere los niveles permitidos en el tráfico social.

Consideramos que esta medida de cuidado solo será exigible en tanto en cuanto el sujeto tenga acceso a los factores de riesgo, en el sentido de que el deber de cuidado es siempre un deber planificable ex ante para el sujeto. En el aspecto subjetivo o personal del tipo no se trata de verificar empíricamente las representaciones de la mente del sujeto, como si se tratara de una supuesta finalidad o intencionalidad potencial con respecto al resultado que se pretendía alcanzar. Tampoco significa verificar la capacidad de motivación del sujeto como requisito del cumplimiento del deber de cuidado preceptuado por la norma penal.

En sede de imprudencia la configuración del vínculo subjetivo o personal entre el sujeto y el hecho no se da de forma lineal a través de la exteriorización de la conducta, pues no sucede, como en los delitos dolosos, una evidente dirección de la conducta a un resultado de peligro o de lesión al bien jurídico que represente una "decisión contraria al bien jurídico protegido". Sino que el vínculo subjetivo se establece en la medida en que sea posible predicar de la conducta del sujeto el adjetivo de descuidada o imprudente. Juicio que se realiza a partir de la contradicción de la conducta con el deber de cuidado debido, exigible al sujeto, siempre y cuando se demuestre que, desde el punto de vista ex ante,

\footnotetext{
1 Feijoo SÁnchez, Bernardo José. Resultado lesivo e imprudencia. Estudio sobre los límites de la responsabilidad penal por imprudencia y el criterio del «fin de protección de la norma de cuidado». Barcelona: J.M. Bosch, 2001, p. 35.

2 Dízz Pita, María del Mar. El dolo eventual. Valencia: Tirant lo Blanch, 1994, pp. 349-350.
} 
tenía el sujeto a su alcance los elementos que configuraban la peligrosidad de su conducta, constitutiva de un riesgo no permitido ${ }^{3}$.

En otras palabras, en el dolo se demuestra la relación subjetiva o personal del sujeto con el resultado verificando, desde el punto de vista ex ante, si la conducta se dirige directa o eventualmente a un resultado de peligro o lesión al bien jurídico afectado ${ }^{4}$; mientras que en la imprudencia la relación subjetiva con el hecho que hace posible la imputación del resultado a la conducta consiste en un juicio individual de contrariedad con el deber de cuidado debido.

Sin embargo, al concebirse así el tipo imprudente surge la siguiente cuestión: si para afirmar la realización del tipo imprudente necesitamos verificar que la conducta se ejecutó con infracción del deber de cuidado superando los niveles del riesgo permitido, es decir, si para identificar la conducta imprudente es menester realizar un juicio de contrariedad a una determinada norma de cuidado, ¿no estamos, en realidad, prejuzgando, en la propia tipicidad, la antijuridicidad de la conducta?

Esta cuestión ya había sido advertida por WELzEL, que defendió la pertenencia del riesgo no permitido a la tipicidad, como elemento normativo del tipo imprudente $^{5}$. Este instituto, que nos permite determinar si la conducta del sujeto entra o no en contradicción con las normas del ordenamiento jurídico o del tráfico social -es decir, si el sujeto en la práctica ha observado (prudencia) o no (imprudencia) las pautas de cuidado objetivas establecidas en los diversos sectores de actividad, a partir de las cuales es posible emitir un juicio de si el riesgo que entraña su conducta es o no admisible- ha sido, incluso, tratado por algún sector de la doctrina como causa de justificación ${ }^{6}$.

Lo que nos lleva a la siguiente cuestión: ¿debemos asumir la concepción tripartita del delito también para los delitos imprudentes, o sería más adecuado

\footnotetext{
3 Corcoy Bidasolo, Mirentxu. El delito imprudente. Criterios de imputación del resultado. Montevideo-Buenos Aires: B de F, 2005, pp. 207 y ss.

4 De acuerdo con la propuesta formulada por DíAz PitA, (1994) p. 321.

5 Confiera al respecto Feijoo SÁnchez (2001), pp. 90-91.

6 Como indica Roxin, Claus. Derecho Penal. Parte General. Tomo I. Fundamentos de la teoría del delito. Luzón Peña, DiegoManuel; Díaz y García Conliedo, Miguel y de Vicente Remesal, Javier (Trads.). Madrid: Civitas, 1997, p. 371, el concepto de riesgo permitido se utiliza en múltiples contextos y se confunde muchas veces con el juicio de antijuridicidad, pues la valoración de si un riesgo es o no permitido requiere un juicio de contrariedad a Derecho. Sin embargo Roxin, lo diferencia de las causas de justificación y lo ubica en la tipicidad, aunque admite la existencia de causas de justificación por riesgo permitido, por ejemplo el consentimiento presunto y la salvaguarda de intereses legítimos (1997), pp. 764-787. Como pone de manifiesto Jakobs, Günther. Derecho Penal, Parte General. Fundamentos y teoría de la imputación. Cuello Contreras, Joaquín y Serrano González de Murillo, José Luis (Trads.). $2^{a}$ Edición. Madrid: Marcial Pons, 1997, p. 245, "sobrepasar el riesgo permitido es requisito positivo del injusto, no es que mantenerse dentro del riesgo permitido sea una causa de justificación”. En la doctrina española, estamos de acuerdo con Muñoz Conde, Francisco y García Arán, Mercedes. Derecho Penal: Parte General. $8^{a}$ Edición. Valencia: Tirant lo Blanch, 2010, p. 310, cuando en relación a los delitos imprudentes manifiestan que el riesgo permitido constituye a priori "un elemento excluyente del carácter imprudente de la acción”. Que esto sea así no impide, como destacan estos autores, que el riesgo permitido pueda ser utilizado, como veremos más adelante, "para marcar los límites de las causas de justificación y de la racionalidad del error sobre los presupuestos objetivos de las mismas" Ídem.
} 
adoptar la concepción bipartita ${ }^{7}$ ?

Generalmente, todas las características de la conducta prohibida que sirven de indicio de la antijuridicidad y la fundamentan se incluyen en el tipo; sin embargo, puede darse el caso de que se incluyan en el propio tipo conceptos normativos o que para llegar a la conducta típica sea necesario elaborar un juicio de contrariedad a la norma de otras ramas del Derecho. Esto sucede, como ponen de manifiesto MuÑoz Conde y GarCía ARÁn, "sobre todo, en los delitos imprudentes, en los que la acción prohibida tiene que ser establecida por el juez con ayuda del criterio de la «diligencia debida»; o [...] en los delitos de comisión por omisión, en los que el ámbito de la autoría tiene que ser completado con el criterio de la «posición de garante». Lo mismo sucede con algunos tipos en los que, para saber cuál es la conducta prohibida, hay que acudir a determinadas características de la antijuridicidad o a referencias normativas que se contienen en otras ramas del Derecho (tipos abiertos y normas penales en blanco)"».

El contenido de la materia de prohibición en casos como estos solo se puede llegar a conocer en un determinado contexto si se tienen en cuenta elementos que también afectan a la antijuridicidad. Sin embargo, como advierten MuÑOz CONDE y García ArÁn, en la medida en que estos elementos deben ser utilizados ya en la delimitación de lo que está o no prohibido por el legislador penal, pasan a pertenecer a la tipicidad y, en consecuencia, "si no se dan se excluye ya la tipicidad misma antes de saber si el comportamiento realizado es o no antijurídico". Cuestión que no debe pasar inadvertida por su trascendencia, como veremos más adelante, en el ámbito del tratamiento del error, puesto que, dependiendo de cómo se consideren esos elementos, como integrantes del tipo o de la antijuridicidad, deberá tratarse el error sobre ellos, respectivamente, como error de tipo o como error de prohibición.

Con respecto, específicamente, a los delitos imprudentes, se puede afirmar el carácter abierto de los tipos penales, en la medida en que la conducta típica no viene determinada con precisión por el legislador penal, debiendo el juez o intérprete establecer el contenido de la conducta imprudente, teniendo como punto de referencia el deber objetivo de cuidado exigible al autor en las circunstancias de los hechos ${ }^{10}$.

\footnotetext{
7 Este tipo de cuestiones repercute, entre otros aspectos, en la configuración de las categorías sistemáticas del delito y en las eximentes de responsabilidad a ella vinculadas, sobre todo en el tratamiento del error en Derecho Penal, con importantes consecuencias en la delimitación del injusto imprudente. Véanse, entre otros, Trapero Barreales, María A. El error en las causas de justificación. Valencia: Tirant lo Blanch, 2004, pp. 43 y ss. ; Muñoz Conde y García Arán, (2010), pp. 253-254.

8 Muñoz Conde y García Arán (2010), p. 254.

9 Muñoz Conde y García Arán (2010), p. 254

10 En este sentido Roxin (1997), p. 1031, pone de manifiesto que "el tipo y la antijuridicidad se confunden entre sí, más en los delitos imprudentes que en los dolosos; pues los tipos imprudentes son 'abiertos' y deben colmarse primero mediante consideraciones generales de imputación que no son posibles sin tener en cuenta la situación concreta y que dificultan la formación de un tipo (o figura) abstracto del delito". De manera similar se manifiestan MuÑoz Conde y GarCía ArÁN (2010), p. 284.
} 
A estos efectos son de gran importancia las reglas de cuidado que, con carácter previo y general, pueden servir de referente al cuidado exigible en determinadas circunstancias. Estas reglas pueden venir descritas en preceptos de normas administrativas, como el Código de la circulación; otras pueden derivar de reglas de la experiencia en el ejercicio de determinadas profesiones, la lex artis (médicos, ingenieros, arquitectos); y puede que las reglas de cuidado sean difíciles de precisar, siendo necesario recurrir a criterios abstractos como «buen conductor», «hombre de inteligencia media», etc. Siendo así que el juicio de realización imprudente de la conducta requiere constatar al menos la contradicción de la conducta del sujeto con alguna de estas reglas. Lo que nos conduce, de momento, a deducir que para la imprudencia es necesario anticipar en la tipicidad el juicio de antijuridicidad, entendida esta como contrariedad formal a las normas jurídicas, pues la imprudencia, en cuanto categoría normativa, consiste justamente en actuar con infracción de un deber objetivo de cuidado derivado de normas previamente establecidas en otros sectores del ordenamiento jurídico.

Esto, sin embargo, no significa adoptar una concepción bipartita del delito imprudente, porque la presencia de elementos normativos en el tipo no tiene por qué conducir necesariamente a la unidad en el tratamiento de la tipicidad y de la antijuridicidad para los delitos imprudentes ${ }^{11}$.

Por otro lado, para mantener la diferenciación entre estas dos categorías sistemáticas en el delito imprudente tampoco hace falta adoptar una especie de antijuridicidad penal, en el sentido predicado por un determinado sector de la doctrina, según el cual, pese a que el juicio de antijuridicidad no pertenezca al Derecho Penal, sino a todo el ordenamiento jurídico, esto no supondría deducir, sin más, la unidad del juicio de antijuridicidad para todos los campos del Derecho $^{12}$. Para los delitos imprudentes, en realidad, es perfectamente posible mantener de forma coherente y sin contradicciones sistemáticas que el injusto se caracteriza por la realización de una conducta típica que no está autorizada

\footnotetext{
11 De la misma forma en que, si se parte de una concepción tripartita para los delitos dolosos, no es necesaria una específica concepción bipartita en aquellos delitos dolosos que contienen elementos normativos en el tipo -como el tráfico ilegal de drogas (art. 368 del Código Penal Español de 1995 -CP 1995-) o la pesca sin autorización (art. 336 CP 1995)-, pudiendo claramente diferenciarse en estos supuestos la conducta típica de la conducta típica, pero justificada, por ejemplo, por el estado de necesidad.

12 Sobre esta base sería posible predicar una antijuridicidad "diferente" para el Derecho Penal con una regulación específica de la exclusión del injusto penal que no eliminase necesariamente para todos los casos la antijuridicidad civil y/o administrativa, según Roxin (1997), pp. 569-572, que, en esta línea reconoce la posibilidad de una específica exclusión del injusto penal propuesta por GÜNTHER, Hans Ludwig. "La clasificación de las causas de justificación en Derecho Penal”. En: Luzón Peña, Diego-Manuel y Mir Puig, Santiago (Coords.). Luzón Peña, Diego-Manuel (Trad.). Causas de justificación y de atipicidad en Derecho Penal. Navarra: Aranzadi, 1995, pp. 48 y ss. En Alemania este último ha sido el que ha formulado la propuesta más significativa al respecto. Desde esta perspectiva sería posible, por ejemplo, que una conducta imprudente por infracción de un deber de cuidado específico de otra rama del Derecho, estuviera justificada por criterios específicamente penales. Véanse también al respecto Baldó Lavilla, Francisco. Estado de necesidad y legítima defensa: un estudio sobre las «situaciones de necesidad》. Barcelona: J. M. Bosch Editor, 1994, p. 278; DíEz RipolLÉs, José Luis. "La categoría de la antijuridicidad en Derecho Penal”. En: Luzón Peña, Diego-Manuel y Mir Puig, Santiago (Coords.). Causas de justificación y de atipicidad en Derecho Penal. Navarra: Aranzadi, 1995, pp. 141 y ss. En nuestra opinión, sin embargo, una causa de justificación autoriza a todos los efectos y en todas las ramas la comisión del tipo.
} 
por una causa de justificación que excluya la antijuridicidad. Con lo cual, la conducta imprudente se caracteriza como tal ya en la propia valoración de la tipicidad y será, además, antijurídica si no está autorizada por una causa de justificación.

Esta estructura escalonada en la valoración de la conducta la aplicamos tanto a los delitos dolosos como a los delitos imprudentes, lo que, además, significa que asumimos la postura de que las causas de justificación desempeñan la misma función valorativa para afirmar o negar la antijuridicidad de la conducta típica, ya sea dolosa o imprudente ${ }^{13}$.

En este sentido, las causas de justificación son aplicables no solo a las acciones dolosas, sino también a las acciones típicas imprudentes, de manera que mantenemos, tanto para los delitos dolosos como para los delitos imprudentes, una concepción tripartita del delito con sus implicaciones.

No obstante, algunas voces en la doctrina española, como por ejemplo PoMAREs Cintas, cuya postura destacamos en virtud del detallado estudio de la cuestión que ofrece su obra, sostienen que "la naturaleza estructural del tipo de injusto imprudente, fundamentalmente contextual, compromete la supervivencia de una similitud metodológica con el hecho doloso; una construcción tripartita no puede abarcar, sino con dificultad y contradicciones, la separación entre la determinación del tipo imprudente y la presencia eventual de causas de justificación"14. Y propone la integración de las situaciones justificantes en la determinación del contenido del deber de cuidado ${ }^{15}$.

Esta propuesta presenta, desde luego, similitud con la teoría de los elementos negativos del tipo, defendida en la doctrina española, entre otros, por Luzón PEÑA, y según la cual el tipo de injusto contiene ya la materia de prohibición o antijuridicidad, de manera que el tipo doloso o imprudente se compone de una parte positiva, formada por el tipo objetivo y subjetivo, y otra negativa, que supone justamente la ausencia de causas de justificación, dando lugar al tipo total de injusto ${ }^{16}$. Aunque no alcancen los mismos resultados, coinciden en la

\footnotetext{
13 Roxin (1997), pp. 286-289, expone la existencia de razones de peso a favor del mantenimiento del tipo como categoría autónoma frente a la antijuridicidad, puesto que su significado no se agota en la averiguación y comprobación del injusto, sino que ambas categorías presentan funciones político-criminales importantes, con significativos efectos sistemáticos. En esa línea de entendimiento también se manifiesta Jescheck, Hans-Heinrich y Weigend, Thomas. Tratado de Derecho Penal: Parte General. Olmedo Cardenete, Miguel (Trad.). $5^{a}$ Edición. Granada: Comares, 2002, pp. 352-354, 634-637.

14 Pomares Cintas, Esther. La relevancia de las causas de justificación en los delitos imprudentes. Granada: Comares, 2004, p. 76. 15 "Como reiteradamente se ha puesto de relieve, la naturaleza sumamente contextual del tipo imprudente a través de la inclusión en su seno «de la contrariedad objetiva al cuidado, del riesgo permitido y del nexo de antijuridicidad», cuestiona el propio plano sistemático en el que se encierran los problemas de la aplicación de causas de justificación; abre la posibilidad de estimarlas ya en el terreno de la formulación de la contrariedad al cuidado. Ello significa que si la base del problema en torno a la valoración de la aplicabilidad de las causas de justificación en la imprudencia se encuentra en la esfera de la tipicidad, también la clave de su solución debemos buscarla y articularla en este mismo estadio" Ibíd., p. 92.

16 Luzón Peña, Diego-Manuel. "Causas de atipicidad y causas de justificación”. En: Luzón Peña, Diego-Manuel y Mir Puig, Santiago (Coords.). Causas de justificación y de atipicidad en Derecho Penal. Navarra: Aranzadi, 1995, pp. 21, 36; LuZÓN PeÑA, Diego-Manuel. Curso de Derecho Penal. Parte General I. Madrid: Editorial Universitas S.A., 1996, pp. 302-303, 329-330.
} 
medida en que conforman una concepción bipartita del delito.

Desde la perspectiva bipartita, Pomares Cintas defiende que la infracción del deber de cuidado solo se puede comprobar a partir de la totalidad de las circunstancias concurrentes, incluso las circunstancias fácticas que originan una causa de justificación y propone "una valoración de las causas de justificación integrada ya en el concepto y análisis del cuidado vinculado a la situación, y por ende, en el marco de la tipicidad del delito imprudente" ${ }^{17}$.

De esta forma postula "una coexistencia plausible entre una concepción tripartita para los delitos dolosos y una diferente (bipartita) en los delitos imprudentes"18. Es decir, partiendo de la diferente naturaleza estructural del injusto del delito imprudente frente al doloso, y de la índole eminentemente contextual de la definición de la contrariedad al cuidado, Pomares Cintas deduce que la valoración de los elementos de una causa de justificación se realiza, sistemáticamente, en el propio análisis del tipo imprudente. La valoración de la tipicidad aparece como el único nivel de imputación, abarcando la apreciación de los elementos o contenidos de valor insertos en la propia situación de conflicto, para la formulación de los márgenes del cuidado debido ${ }^{19}$.

Todo esto lo aboca a otorgar una función cualitativamente distinta a las causas de justificación en el ámbito de la imprudencia, que altera la relación entre fundamentación del injusto y su exclusión, para afirmar que el tipo imprudente no es meramente indiciario de la antijuridicidad, sino que directamente fundamenta la antijuridicidad ${ }^{20}$. Así, por ejemplo, considera que si el conductor

\footnotetext{
A favor de la teoría total del injusto que queda configurada por la teoría de los elementos negativos del tipo en la doctrina alemana Schünemann, Bernd. "La función de la delimitación de injusto y culpabilidad". En: Schünemann, Bernd y De Figueiredo Dias, Jorge (Coords.), Fundamentos de un sistema europeo del Derecho Penal. Libro-Homenaje a Claus Roxin, Barcelona: J. M. Bosch, 1995, pp. 222-225, 235-238. Como partidario de algunas cuestiones de fondo desarrolladas en el seno de la teoría de los elementos negativos del tipo, Mir Puig, Santiago. Derecho Penal: Parte General. $7^{a}$ Edición. Barcelona: Reppertor, 2004, pp. 162-166, 416-425, que apartándose del concepto de tipo total de injusto, está de acuerdo con que la concurrencia de causas de justificación excluye (no la propia tipicidad, sino) la presencia del supuesto de hecho antijurídico. Cabe, asimismo, destacar que su propuesta no se ajusta a una «verdadera» concepción bipartita del delito, dado que la tipicidad sigue ocupando una función sistemática en la teoría del delito -al menos una «función de llamada»- sin estar completamente supeditada o absorbida por la constatación de la antijuridicidad

17 Pomares Cintas (2004), pp. 92-93, cursivas en el original.

18 Pomares Cintas (2004), p. 124. Mientras que para los partidarios de la teoría de los elementos negativos del tipo, la concepción bipartita es válida tanto para los delitos dolosos como para los imprudentes.

19 Según defiende, "la presencia de los elementos que originan una causa de justificación elimina la contrariedad al cuidado de la conducta arriesgada en cuestión; con arreglo a las circunstancias dadas, no se realiza ya el concepto de imprudencia, y con ello, la tipicidad de la conducta. O de otro modo, si bajo la totalidad de las circunstancias concurrentes, se afirma la existencia de una conducta que infringe las exigencias del cuidado requerido o supera los márgenes del riesgo permitido en la concreta situación, se habrá realizado definitivamente una conducta imprudente antijurídica" POMARES CinTAS (2004), p. 256.

20 En opinión de Pomares Cintas (2004), p. 124, cursivas en el original, las causas de justificación "se convierten en factores integrantes de la propia regulación de las exigencias de cuidado. Esto es, modifican o corrigen el alcance de los deberes de cuidado que incumben al autor, para establecer si éste ha desatendido o no las exigencias de conductas indicadas en una tal situación de 'necesidad', o de 'defensa', a las que aluden las hipótesis de investigación. En consecuencia, son las peculiaridades típicas del delito imprudente las que promueven un concepto diverso de vinculación del juicio de imprudencia y la existencia de causas de justificación, en el que la tendencia se dirige a compartir y reducir procesos valorativos, esto es, un reduccionismo dogmático frente al sistema del delito doloso". Todo lo cual le conduce a concluir que "no se podrá
} 
"A" de un vehículo realiza una maniobra arriesgada para no colisionar con otro vehículo "B", que no atendió a la señal de stop, poniéndose así "A" a salvo, y como consecuencia de esta maniobra " $\mathrm{A}$ " invade el carril contrario y termina ocasionando un accidente lesionando a los ocupantes de un tercer vehículo "C", la acción arriesgada de salvaguarda debe ser valorada ya en la tipicidad, para negar la existencia de una conducta típica imprudente. Es decir, según defiende Pomares Cintas, la valoración de la maniobra peligrosa que se realiza en el seno de una situación de necesidad justificante "influye en la graduación de las exigencias de cuidado hasta el punto de negar la existencia de la imprudencia"21.

Sin embargo, pese a la coherencia de los argumentos expuestos, este planteamiento, que, como ya hemos puesto de manifiesto, coincide en muchos aspectos con la teoría de los elementos negativos del tipo ${ }^{22}$, conduce a una serie de inconvenientes.

En primer lugar porque se pierde, con la simplificación del razonamiento, la diferencia sustancial que existe entre la delimitación de la relevancia penal de una determinada conducta en el ámbito de la tipicidad, y la ponderación de si se puede permitir la realización de una conducta típica cuando se dan los presupuestos de una determinada causa de justificación, repercutiendo, asimismo, en la valoración de la responsabilidad civil ex delito en sede de la jurisdicción penal, pues a este respecto tiene importancia, por ejemplo, caracterizar una conducta como atípica o considerar que se trata de una conducta típica pero justificada por el estado de necesidad (art. 118. $\left.3^{\circ} \mathrm{CP} 1995\right)$.

En segundo lugar, se reduce sustancialmente la amplitud de matizaciones valorativas factibles a partir de la consideración de la antijuridicidad como categoría sistemática autónoma, dificultando -al menos en España- la posibilidad de realizar una coherente graduación del injusto ${ }^{23}$.

\footnotetext{
sostener que las causas de justificación tienen aquí la función de compensar o permitir la infracción de un deber de cuidado existente, la realización de una conducta en sí imprudente; su eficacia trasciende a esta función y su significación experimenta una connotación muy distinta. Las situaciones que corresponden a una causa de justificación se conciben, esencialmente, como criterios que colaboran en la delimitación del contenido del deber de cuidado; esto es, desempeñan, en los delitos imprudentes, una tarea de modificación o reducción de las exigencias de conducta que incumban al autor atendiendo a esa situación, influencia que se desenvuelve, por tanto, en el plano de la tipicidad, en un único paso de imputación” Ibíd., p. 257, cursivas en el original.

21 Pomares Cintas (2004), p. 126.

22 Concretamente porque conduce a aceptar que "la tipicidad implica siempre la antijuridicidad y, viceversa, la presencia de causas de justificación excluye la tipicidad” Mir Puig (2004), p. 163.

23 En este sentido la crítica de Valle MuÑiz, José Manuel. "Fundamento, alcance y función de las causas de justificación incompletas en el Código penal español”. Anuario de Derecho Penal y Ciencias Penales, No 40, 1992, pp. 574-577, ha algunas de las dificultades sistemáticas a que conduce adoptar la teoría de los elementos negativos del tipo, al menos en los delitos dolosos. Aunque cabe reconocer que el desarrollo de la teoría de los elementos negativos del tipo realizada por Luzón PEÑA (1996), pp. 480, 482, 485, ha logrado alcanzar respuestas coherentes y favorables a la graduación del injusto incluso para los delitos imprudentes. En base a estos autores, cuando nos referimos a la graduación o disminución del injusto no queda la menor duda de que nos referimos a un hecho típico y antijurídico (se trata de un hecho injusto), pero en el cual han repercutido circunstancias que valoradas en sede de antijuridicidad disminuyen significativamente el grado de desvalor del injusto y cuya presencia fundamenta una rebaja en la medición de la pena.
} 
En tercer lugar, porque conduce al tratamiento unitario del error sobre los elementos del tipo y el error sobre los presupuestos objetivos de las causas de justificación, que de ser aplicado exclusivamente en el ámbito de la imprudencia (ya que para los delitos dolosos Pomares Cintas admite una concepción tripartita del delito), posibilita un espacio de punibilidad más rígido e inflexible en comparación con los delitos dolosos. Volveremos a esta cuestión más adelante.

Asimismo, si se incluye la valoración de los elementos de una causa de justificación en la tipicidad para realizar el juicio acerca del deber de cuidado debido, esto puede llegar a producir una doble repercusión: por un lado significaría que el tipo objetivo pasa a estar integrado -a diferencia del delito doloso- por los elementos objetivos de la antijuridicidad y, por otro lado, si se mantiene la necesidad de un tipo subjetivo en el delito imprudente, este habría de proyectarse sobre los requisitos objetivos del tipo (y de la antijuridicidad). Lo que nos conduce a la siguiente cuestión: ¿el elemento subjetivo del tipo englobaría entonces el conocimiento o cognoscibilidad de que se actúa de forma antijurídica (sin la presencia de elementos de justificación)?

Este planteamiento, resulta de difícil configuración en la práctica en el ámbito de los delitos imprudentes, pues esa cuestión siempre ha sido elaborada teniendo como referente la conducta dolosa ${ }^{24}$. Además, supone tener en cuenta elementos de la culpabilidad (conciencia de la antijuridicidad) en el injusto ${ }^{25}$.

Al mismo tiempo, puede que afecte a la delimitación de la tipicidad, reper-

24 Como pone de manifiesto Trapero Barreales (2004), pp. 603 y ss., esa cuestión es tratada en la doctrina como error inverso sobre la concurrencia en el hecho doloso de los presupuestos objetivos de justificación. Su abordaje, como veremos más adelante en el texto, depende del tratamiento jurídico de los elementos subjetivos de justificación, es decir, "de si es necesario o no que el sujeto actúe con el fin o ánimo de actuar objetivamente justificado (con ánimo de defensa, de salvación, de cumplir el deber, etc.), o si, por el contrario, basta con que tenga conocimiento de la concurrencia objetiva de la situación de justificación para que desaparezca el desvalor de acción al hecho doloso (o, desde la concepción objetiva, no es necesario tampoco este conocimiento para la exclusión del desvalor de acción del delito doloso)” Ibíd., p. 605, las cursivas son nuestras. El planteamiento de esa cuestión sería de difícil trasposición al ámbito de los delitos imprudentes, en la medida en que el elemento subjetivo de las causas de justificación requeriría la representación de un resultado de lesión, representación incompatible con la estructura de la imprudencia.

25 Éstas, en efecto, constituyen algunas de las principales críticas dirigidas a la teoría de los elementos negativos del tipo, como consecuencia de la valoración de las causas justificación en la tipicidad. Aunque en la construcción de LuZÓN PeÑa (1996), p. 473, la parte negativa del tipo que abarca la ausencia de causas de justificación y, por tanto, el juicio de antijuridicidad en el injusto, no requiere la consciencia de la antijuridicidad, siendo suficiente la representación de los presupuestos objetivos (descriptivos o normativos) del tipo y de las causas de justificación. En el intento de salvar su planteamiento de críticas similares a las esbozadas contra la teoría de los elementos negativos del tipo, y de la crítica de que el elemento subjetivo de las causas de justificación requiere la representación de un resultado de lesión -representación incompatible con la estructura de la imprudencia-, POMARES CinTas (2004), p. 190, defiende que dicho elemento subjetivo en el juicio de contrariedad al deber de cuidado sólo requiere el "conocimiento de la concurrencia de las circunstancias fácticas correspondientes a la causa de justificación y en dirección a la finalidad señalada". Además, aclara: "si el presupuesto subjetivo contribuye a reducir las exigencias del cuidado en la puesta en peligro del bien jurídico de que se trate cuando el autor, mediante una acción necesaria, se dirige a salvar un interés preponderante, su ausencia excluirá esa posibilidad: la conducta entonces será, definitivamente, contraria al cuidado, imprudente, y el resultado lesivo será imputado objetivamente a ella" Ibíd., 2004, p. 191, cursivas en el original. De modo que el tipo subjetivo de la conducta imprudente, en los casos en que estuviera presente el presupuesto fáctico de una causa de justificación, quedaría integrado también por el desconocimiento de dicha circunstancia justificante, lo que no significa, para que quede claro, conciencia de la antijuridicidad (elemento de la culpabilidad). Con estos matices, tanto la postura de Luzón PeÑa, como la de Pomares Cintas, logran contestar a las críticas esbozadas para sostener con coherencia la concepción bipartita del delito, aunque no estemos de acuerdo con ella. 
cutiendo significativamente en el ámbito de la punibilidad por imprudencia, como veremos a continuación.

\subsection{Efectos Del Desconocimiento de los Elementos objetivos De UNA} CAUSA DE JUSTIFICACIÓN EN EL DELITO IMPRUDENTE

En efecto, la conducta imprudente, objetivamente justificada, realizada por el sujeto sin el conocimiento de la presencia de los elementos objetivos de la causa de justificación ${ }^{26}$, ¿cómo ha de ser valorada?

A este respecto Pomares Cintas defiende que la valoración de la conducta no cambia, sigue siendo típica y punible, sin apreciar en este contexto siquiera la posibilidad de que la presencia objetiva de la situación justificante pueda dar lugar a la graduación del injusto. En su opinión, en este caso habría que castigar la conducta imprudente con la pena del delito consumado porque "si el presupuesto subjetivo contribuye a reducir las exigencias del cuidado en la puesta en peligro del bien jurídico de que se trate cuando el autor, mediante una acción necesaria, se dirige a salvar un interés preponderante, su ausencia excluirá esa posibilidad: la conducta entonces será, definitivamente, contraria al cuidado, imprudente, y el resultado lesivo será imputado objetivamente a ella"27.

Es decir, a pesar de reconocer la necesidad y exigencia de la vertiente subjetiva de la justificación, Pomares Cintas no logra alcanzar, como consecuencia de su concepción bipartita del delito imprudente, las ventajas que, desde una concepción tripartita, se pueden llegar a conquistar de forma coherente en beneficio de la graduación del injusto ${ }^{28}$. En efecto, desde la concepción tripartita del delito,

\footnotetext{
26 Como ejemplo imagínese el caso propuesto por LuZÓn PeÑa (1996), p. 513, de dos trabajadores que bajan por las escaleras de un edificio una viga de gran envergadura que, por descuido, se les escapa de las manos y resulta por chocarse con la puerta de una vivienda derrumbándola, y como consecuencia salvan a una persona que estaba siendo agredida por el dueño de la vivienda. Para una aproximación a las propuestas desarrolladas en este ámbito vid. VALLE MuÑiz, José Manuel. "La naturaleza graduable de lo injusto y la actuación en desconocimiento del presupuesto objetivo de una causa de justificación". En: Silva SÁnchez, Jesús María (Ed.). Política criminal y nuevo Derecho Penal. Libro homenaje a Claus Roxin. Barcelona: Bosch, 1997, pp. 441 y ss.; Carbonell Mateu, Juan Carlos. "El sistema de justificación en el art. 20 CP/1995". En: Quintero Olivares, Gonzalo y Morales Prats, Fermín (Coords.). El nuevo Derecho penal. Estudios penales en memoria del Profesor José Manuel Valle Muñi: Navarra: Aranzadi, 2001, pp. 124 y ss.; Cuello Contreras, Joaquín. "Elemento objetivo y subjetivo de las causas de justificación”. En: Quintero Olivares, Gonzalo y Morales Prats, Fermín (Coords.). El nuevo Derecho penal. Estudios penales en memoria del Profesor José Manuel Valle Muñiz: Navarra: Aranzadi, 2001, pp. 148 y ss.; SANz Morán, Ángel José “Los elementos subjetivos de justificación”. En: Quintero Olivares, Gonzalo y Morales Prats, Fermín (Coords.). El nuevo Derecho Penal. Estudios penales en memoria del Profesor José Manuel Valle Muñiz. Navarra: Aranzadi, 2001, pp. 724 y ss.; Pomares Cintas (2004), pp. 135 y ss.

27 Pomares Cintas (2004), p. 191.

28 Desde la teoría de los elementos negativos del tipo, al menos Luzón PeÑa (1996), p. 604, logra alcanzar una solución materialmente más justa -aunque no estemos de acuerdo con su postura- en los casos de desconocimiento de la situación de defensa, que resulta en la no punibilidad de la conducta imprudente: "si hay desconocimiento de la situación de defensa unido a una actuación imprudente, ciertamente habrá ilicitud genérica, extrapenal (por la actividad imprudente), pero no penalmente típica, pues este solo desvalor de la acción sería impune al faltar desvalor de resultado (si el medio defensivo interpuesto inconscientemente era objetivamente necesario y por tanto la situación está objetivamente justificada), que es esencial para la consumación y punición del delito imprudente, a diferencia de lo que ocurre en el doloso", cursivas en el original.
} 
y a partir del reconocimiento de que las causas de justificación se constituyen de elementos objetivos y subjetivos, se pueden realizar combinaciones que permiten un margen de valoración más amplio de la conducta típica ${ }^{29}$.

Tomemos como referente la solución propuesta por Roxin -que defiende una concepción tripartita del delito y, asimismo, la aplicabilidad de las causas de justificación a los delitos imprudentes-. Este autor considera, tanto para los delitos dolosos como para los imprudentes, que la justificación presupone la comprensión de los límites objetivos de la justificación y el conocimiento de la situación justificante ${ }^{30}$.

Así, respecto a los delitos dolosos, defiende Roxin, que "(s)i al sujeto le falta el elemento subjetivo de justificación (es decir, según la concepción aquí defendida: si actúa objetivamente de forma correcta, pero desconociendo la situación de justificación), entonces existe una tentativa (inidónea). El sujeto no responde por tanto penalmente en tanto no esté castigada la tentativa [...]. Existe una mera tentativa porque el resultado de injusto objetivamente no se ha producido y el desvalor de la acción por sí solo únicamente puede fundamentar una tentativa. Se trata aquí de una aplicación directa y no sólo analógica de las reglas de la tentativa" 31 .

Y el mismo razonamiento lo utiliza en sede de imprudencia en "supuestos de hecho en los que el sujeto que actúa imprudentemente efectúe algo objetivamente legítimo, sin conocer siquiera la situación de legítima defensa. 'Así cuando al manejar descuidadamente un arma se escapa un disparo que hiere al agresor del que sin embargo nada sabía el sujeto'; o cuando el sujeto que no sospecha nada 'evita en el último momento, atropellándolo por torpeza, la agresión de un atracador que utiliza la trampa del coche, habiendo simulado un accidente'. En tales casos no se produce la justificación. Pero como la realización del tipo estaba objetivamente permitida, falta el desvalor del resultado. Resta solo un desvalor

29 A este respecto véase por todos Valle Muñiz (1992), pp. 563-612; Valle Muñiz (1997), pp. 460-467.

30 Roxin (1997), pp. 597-600. También Mir Puig, (2004), p. 463, admite la posibilidad de apreciar el estado de necesidad justificante en los delitos imprudentes, y pone como ejemplo el caso en que "(p)ara procurar asistencia a un herido grave en carretera, alguien lo conduce al hospital a velocidad excesiva, causando lesiones graves a un peatón". Pero MIR Puig especifica que la posibilidad de apreciar el estado de necesidad justificante en los delitos imprudentes no implica que el sujeto resulte impune cuando la situación de necesidad haya sido provocada de forma imprudente, refiriéndose aquí al planteamiento de la actio ilícita in causa (Ibíd., pp. 467-469). En contra del planteamiento de la actio illicita in causa, por ejemplo, Roxin (1997), pp. 641, 700-701, entre otros argumentos porque conduciría a admitir que la misma acción sea a la vez tanto jurídica como antijurídica: conforme a Derecho en relación al estado de necesidad, y antijurídica en relación a la imputación del resultado a la precedente creación de un riesgo no permitido -la provocación imprudente de la situación de necesidad- illicita in causa. De manera similar ya se había manifestado Alonso Álamo, Mercedes. "La acción «libera in causa»". Anuario de Derecho Penal y Ciencias Penales, No 42,1989, pp. 76-79, durante la vigencia del Código Penal español de 1973, con el rechazo a la posibilidad de fundamentar el castigo de una acción precedente en base al planteamiento de la aiic imprudente. Teniendo en cuenta que el art. 20.5.2 ${ }^{\circ} \mathrm{CP} 1995$ establece como presupuesto del estado de necesidad que la situación de necesidad no haya sido provocada intencionadamente por el sujeto, e interpretando que en dicho dispositivo el legislador penal se refiere a la provocación dolosa del estado de necesidad, consideramos que resultan más adecuadas las posturas de Roxin y Alonso Álamo, de lo contrario se ampliaría la punibilidad allí donde el legislador no especifica el castigo de la acción imprudente.

31 Roxin (1997), pp. 600-601. En el mismo sentido JescheCK y Weigend (2002), pp. 352-354. 
de la acción, o sea, una tentativa imprudente, que por regla general no es punible. Se corresponde por tanto con la opinión dominante. Y es además correcto en la consecuencia final en que normalmente no son precisos elementos subjetivos de justificación para la impunidad en el delito imprudente. Sin embargo, a menudo no se subraya con suficiente claridad que esto rige sólo para la punibilidad, y no también para la justificación"32.

Esta postura, que ha sido adoptada por un significativo sector de la doctrina española ${ }^{33}$, demuestra, y a pesar de las críticas $^{34}$, la posibilidad de que la presencia del valor objetivo de resultado permita modificar el injusto, en este caso, para afirmar la tentativa inidónea (impune en los delitos imprudentes).

Otra vía de solución distinta, que se encamina claramente en dirección a la graduación del injusto, consiste en estimar, en los supuestos de ausencia del elemento subjetivo de justificación, la eximente incompleta, posibilidad que viene dada en la legislación española en el art. 21.1º , en relación con el art. 68 CP 1995. Esta posibilidad, defendida por un importante sector de la doctrina española ${ }^{35}$,

32 Roxin (1997), pp. 1032-1033. Sin embargo, para JESCHECK y WEIGEND (2002), p. 634, dado que no es punible la tentativa para los delitos imprudentes de resultado, bastaría con la presencia de los requisitos objetivos para aplicar la causa de justificación. Aunque según especifica, para los delitos de mera actividad imprudente sí deberán concurrir tanto los requisitos objetivos de la situación justificante como el requisito subjetivo, de manera que debe el sujeto reconocer esta situación para que la conducta típica de mera actividad esté justificada.

33 Entre otros, por Luzón Peña (1995), pp. 37-40; Luzón Peña (1996), pp. 485, 603; Trapero Barreales, María A. Los elementos subjetivos en las causas de justificación y de atipicidad penal. Granada: Comares, 2000, pp. 339-340, 350-351, 394, que asimismo asume la solución de la tentativa inidónea específicamente en relación a la actuación imprudente con desconocimiento de la concurrencia de los presupuestos objetivos de la causa de justificación, pp. 486-491; Sánz Morán (2001), pp. 739-741. Por su parte, Muñoz Conde y García Arán (2010), p. 313, también aprecian la posibilidad de aplicar en los casos de falta del elemento subjetivo de justificación la solución de la tentativa: "la ausencia del elemento subjetivo de justificación en una situación objetivamente justificada mantiene el desvalor de acción, aunque no el del resultado, por eso sólo puede hablarse de una tentativa de delito que el sujeto creía que cometía, pero no de consumación, aunque también podría valorarse como una eximente incompleta".

34 En efecto, Valle MuÑiz, que comparte el punto de partida metodológico de Roxin en la configuración del sistema del Derecho Penal y de las categorías del delito a partir de las finalidades político criminales que legitiman la intervención punitiva, considera, sin embargo, inadecuada y paradójica la solución de la tentativa al "afirmar sin más que la presencia de los presupuestos objetivos de justificación hace desaparecer el desvalor de resultado presente en la perfección típica. Afirmar sin más la identidad valorativa entre el supuesto de querer matar a un hombre sin conseguirlo y el supuesto de matarlo efectivamente, pero desconociendo la presencia de un situación justificante" VALLE MuÑIz (1997), p. 457, cursivas en el original. En este sentido sostiene que "la constatación de la presencia objetiva de intereses que positivamente pretenden contrarrestar la carga negativa de la desvaloración típica, no puede modificar el hecho de que se ha dado un resultado típico" Ídem. Para luego encauzar la cuestión, bajo nuestro punto de vista acertadamente, en el ámbito de la graduación del injusto.

35 Aboga por la posibilidad de graduar el injusto en el seno de la antijuridicidad y estimar la eximente incompleta -estando presente el presupuesto objetivo de la causa de justificación-, que repercute en la medida de la culpabilidad, especialmente VALLE MuÑIz, (1997), pp. 457-467. Como pone de manifiesto este autor, "la menor gravedad del castigo [...] obedece a una disminución del contenido del injusto", en el sentido de que "si la explicación de las causas que eximen de responsabilidad criminal se fundamenta en la exclusión del injusto o de la culpabilidad, su apreciación incompleta podrá permitir la aplicación de la pena inferior en uno o dos grados a la señalada por la ley, en la medida en que se constate una disminución de la intensidad de la desvalorización de la conducta, o del reproche de culpabilidad por el hecho cometido" Ibíd., p. 461. Y esto porque la antijuridicidad, tal como defiende, no se limitaría "a confirmar la presencia del injusto típico, o a declarar la autorización del comportamiento penalmente relevante por la preponderante apreciación de los intereses aportados por la justificación, sino que en su sede puede apreciarse también una función de graduación del injusto [...] que recae, lógicamente, sobre la apreciación incompleta de las causas de justificación” Ibíd., p. 463. En contra de esta posibilidad argumenta Trapero Barrero (2000), p. 385, que el conocimiento de los presupuestos objetivos de una causa de justificación constituye también un requisito esencial de la misma y en este sentido representa también un presupuesto para la apreciación de la eximente, incluso de la causa de justificación incompleta: "la eximente incompleta tiene lugar en 
fue inicialmente propuesta por Mir $\operatorname{PUIG}^{36} \mathrm{y}$, a pesar de que sus planteamientos le acerquen en cierta medida a la teoría de los elementos negativos del tipo, no se confunden con una auténtica concepción bipartita del delito, especialmente porque la tipicidad sigue ocupando una función sistemática en su concepción de delito, que no está completamente absorbida o supeditada a la constatación de la antijuridicidad.

Concretamente, cuando la falta de conocimiento de los presupuestos objetivos de la justificación se da en un delito imprudente, Mir Puig considera que deberá apreciarse la eximente de forma incompleta: “Así, en el ejemplo que propone LuZón de unos empleados que llevan por la escalera de un edificio una viga, golpean y rompen por descuido la puerta de una casa y al hacerlo salvan sin saberlo a una persona agredida ilegítimamente por el dueño de la casa y que logra escapar a la agresión, no debe admitirse la exención completa, como propone aquel autor, sino la eximente incompleta de la legítima defensa. No puede considerarse que en este caso el delito imprudente [probablemente se refiera a las lesiones imprudentes provocadas al dueño de la casa con el derrumbe de la puerta que ha posibilitado la fuga de la víctima agredida] no se ha consumado y la exención viene obligada por el hecho de que la ley no castiga la tentativa imprudente. La solución alemana de apreciar la pena de la tentativa por analogía cuando falta el elemento subjetivo de justificación no supone desconocer que se ha producido una efectiva consumación del delito. La consumación solo depende del alcance de la lesión típica - y ello ha de valer también para quien admita la teoría de los elementos negativos del tipo. La solución de la eximente incompleta tiene la ventaja de permitir distinguir con más claridad la cuestión de la tentativa -atípica en los delitos imprudentes- y de la subsistencia del desvalor de acción cuando falta el elemento subjetivo de justificación -situación que puede darse en un tipo imprudente igual que en uno doloso" 37 .

Es evidente la disparidad de las consecuencias a que conduce asumir una postura u otra, que van desde la posibilidad de punir la conducta imprudente (concepción bipartita del delito imprudente), a considerar esta conducta como tentativa imprudente (modificación de la estructura típica del injusto), impune en el Derecho Penal español, pasando por la posibilidad de atenuar la pena (graduación del injusto que repercute en la medida de la culpabilidad y la pena) ${ }^{38}$. Cabe preguntarse qué postura es la más adecuada.

\footnotetext{
los casos de excesos intensivos dolosos o imprudentes, esto es, en el caso de concurrencia de los requisitos esenciales de la correspondiente causa de justificación y sabiendo el sujeto que tales presupuestos concurren objetivamente, pero realizando una conducta conscientemente más lesiva y por tanto innecesaria en la protección del bien jurídico amparado por la eximente o cuando la lesión innecesaria se debe a una conducta descuidada o imprudente, pero también en este caso teniendo conocimiento de la concurrencia de los presupuestos objetivos de la causa de justificación".

36 Mir Puig, Santiago. "Adiciones de Derecho español al \ 31”. En: Jescheck, Hans Heinrich. Tratado de Derecho Penal. Parte General. Volumen 1. Traducción y adiciones de Derecho español por Mir Puig, Santiago y MuÑoz Conde, Francisco. Barcelona: Bosch, 1981, p. 457; Mir Puig (2004), pp. 162-166, 416-425.

37 Mir Puig (2004), p. 421.

38 Para un estudio más profundo de estas propuestas en el tratamiento de la ausencia del elemento subjetivo de justificación véase, por todos, Trapero Barreales (2000), pp. 290-394, 477 y ss.
} 
Antes de responder a esta pregunta, pasaremos al análisis de otra problemática, de modo que podamos ofrecer al final una solución de conjunto que posibilite una visión global de la delimitación de la imprudencia.

\subsection{EFECTOS DE LA SUPOSICIÓN ERRÓNEA DE LOS PRESUPUESTOS OBJETIVOS DE} UNA CAUSA DE JUSTIFICACIÓN EN EL DELITO IMPRUDENTE

Nos referimos ahora precisamente a la cuestión inversa: ¿cómo debe ser valorada la conducta imprudente cuando esta es realizada en la suposición errónea de que concurren los presupuestos objetivos de una causa de justificación, es decir, cuando, dándose el elemento subjetivo, lo que falta es el elemento objetivo de la justificación? ${ }^{39}$

Ya habíamos adelantado más arriba la existencia de implicaciones entre la concepción del delito y el tratamiento del error.

Si partimos de la teoría de los elementos negativos del tipo en el ámbito de la imprudencia o, con Pomares CinTAs, de una concepción personal del injusto y bipartita del delito imprudente -en que la antijuridicidad se prejuzga en la tipicidad, incluso los aspectos objetivo y subjetivo de las causas de justificación,- más allá de los serios inconvenientes que se derivan de la reunión de la tipicidad y la antijuridicidad ${ }^{40}$, esta concepción supone tratar uniformemente el error de tipo y el error sobre los presupuestos objetivos de la causa de justificación $^{41}$, con la consecuente repercusión en el ámbito de la punibilidad.

Como ejemplo imagínese el caso del conductor " $\mathrm{A}$ " que, viendo los destrozos de un coche en la carretera, cree erróneamente que el conductor accidentado "B" se encuentra gravemente herido y que peligra su vida, y conduce a gran velocidad al hospital. En el trayecto colisiona, debido a su impericia al volante, con otro vehículo causando lesiones al conductor " $C$ ". De considerar este error como error de tipo, si es considerado invencible no hay conducta punible, porque se elimina el tipo de injusto imprudente.

\footnotetext{
39 El error sobre los presupuestos objetivos de una causa de justificación se puede enfocar desde aspectos distintos de la conducta y puede conducir a diferentes soluciones según se parta de una concepción bipartita o tripartita del delito; según se conciban las causas de justificación de forma estrictamente objetiva, o se admita la presencia de elementos subjetivos de justificación; según el punto de partida teórico adoptado en el tratamiento del error, etc. A este respecto véanse, entre otros, Valle Muñiz (1997), p. 441; Traperro Barreales (2004), pp. 43 y ss., cuestiones que por motivos obvios no podemos aquí tratar en profundidad, aunque sí de forma tangencial para indicar los aspectos a tener en cuenta en la delimitación de la imprudencia en virtud de sus peculiaridades ya que -a diferencia del delito doloso- el delito imprudente no admite como injusto penalmente típico la tentativa, ni, tampoco, para la mayoría de la doctrina, la participación. Acerca del error en Derecho Penal véanse, además, Muñoz Conde, Francisco. El error en Derecho Penal. Valencia: Tirant lo Blanch, 1989, pp. 21-92; LuZÓn PeÑa (1996), pp.439-486; Roxin (1997), pp. 459-471, 579-586.

40 A este respecto, véase, por todos Roxin (1997), pp. 286-289.

41 Pues todas las circunstancias relevantes en la antijuridicidad ya son tenidas en cuenta en el tipo por Roxin, pp. 284285. Como pone de manifiesto Luzón PeÑa (1996), p. 300, una de las consecuencias prácticas de la teoría de los elementos negativos del tipo se produce justamente en materia de error "pues el error sobre la concurrencia de los elementos de las causas de justificación es un error sobre elementos de una parte del tipo, la negativa, y por tanto es un error de tipo y no un error de prohibición".
} 
Cuando se trata de un error vencible, desde la concepción bipartita del delito imprudente defendida por POMARES CINTAS, la vencibilidad del error acerca del presupuesto objetivo de la causa de justificación (la gravedad de las heridas de "B") afecta a la valoración de las exigencias de cuidado para afirmar la imprudencia de "A", que lesionó al conductor de otro vehículo " $\mathrm{C}$ " y que será punible como tal, sin atenuación de la pena como consecuencia de la vencibilidad del error acerca de la situación justificante. Lo que, desde luego, contribuye a una mayor rigidez en la medición de la pena del delito imprudente, en comparación al doloso (si, como Pomares CinTAS, se admite una concepción tripartita para los delitos dolosos).

Por su parte, desde la teoría de los elementos negativos del tipo defendida por LUZÓN PEÑA es posible alcanzar en este ámbito una solución materialmente más justa. Este autor parte de que todos los casos de error sobre los presupuestos objetivos de las causas de justificación deben ser valorados, desde la perspectiva ex ante y con baremos objetivo-generales, como error de tipo (negativo) ${ }^{42}$. Así, en el caso en que se realice, por ejemplo, una conducta imprudente para salvar la vida de un herido grave en carretera (situación de necesidad), pero el sujeto se encuentre sumido en un error vencible acerca de los presupuestos objetivos de la causa de justificación -que para Luzón será siempre un error objetivamente vencible-, no se aplica la causa de justificación, ni siquiera en su forma incompleta, de modo que permanece el injusto imprudente inalterado, cabiendo solo la posibilidad de valorar, en la culpabilidad, la trascendencia del error desde la perspectiva individual, es decir, si era personalmente vencible o no ${ }^{43}$. La graduación del injusto imprudente entonces solo sería posible en el caso de que, estando presentes los presupuestos de la causa de justificación, el sujeto en situación de necesidad se excediera, por ejemplo, en la respuesta, en cuyo caso LuzÓn PeÑa defiende la posibilidad de aplicación de la causa de justificación incompleta, con la consecuente atenuación de la pena del injusto imprudente ${ }^{44}$.

Asimismo, defiende la posibilidad de que concurran en el mismo supuesto de hecho la causa de justificación incompleta y un error en los límites, que para este autor constituye un error de prohibición, admitiendo, así, la posibilidad de una doble atenuación de la pena: fundamentada en el menor desvalor del injusto y en la menor medida de la culpabilidad.

\footnotetext{
42 Luzón Peña (1996), pp. 477-480; Luzón PeÑa, Diego-Manuel “Caso fortuito y creencia razonable: error objetivamente invencible y consentimiento presunto, como causas de justificación o de exclusión de la tipicidad penal”. Revista General de Derecho Penal, No 9, 2008, pp. 7-9.

43 Adoptando la teoría restringida de la culpabilidad y la teoría de los elementos negativos del tipo, DíAz y García ConLLEDO, Miguel. El error sobre elementos normativos del tipo penal. Madrid: La Ley, 2008, pp. 170-178, llega a las mismas conclusiones. Esta postura, sin embargo, puede ser criticada porque conduce, como consecuencia de la concepción bipartita del delito, a la equiparación del error en los presupuestos objetivos de las causas de justificación al error de tipo, lo que supone la modificación en la caracterización del tipo de injusto cuando se trata de una conducta dolosa -ya que el error vencible en los presupuestos objetivos de la causa de justificación tratado como error de tipo provoca que la conducta se caracterice como imprudente- mientras que cuando se trata de una conducta imprudente dicho error no produce ningún efecto.

44 LuZÓn PeÑa (1996), pp. 482-484.
} 
A conclusiones similares se llega desde concepciones cercanas a la teoría de los elementos negativos del tipo. Así, por ejemplo, Mir PuIG, que también defiende que estos casos deben ser tratados de forma similar al error de tipo, concretamente, como un error de tipo negativo (el error incide sobre el supuesto típico de una causa de justificación $)^{45}$. Desde la postura de MiR PUIG, la conducta imprudente llevada a cabo, por ejemplo, para dar lugar a una acción de salvaguarda para conjurar un mal irreal, sigue siendo punible como tal, sin que pueda verse beneficiada -al menos no lo manifiesta expresamente- con la atenuación de la pena como consecuencia del error vencible en la apreciación de la situación justificante ${ }^{46}$. La valoración del error se hará a partir de criterios o baremos objetivo-generales, desde la perspectiva ex ante, para decidir la vencibilidad o no del error acerca del presupuesto de la causa de justificación.

Si partimos de una concepción personal del injusto y tripartita del delito, diferenciando la tipicidad de la antijuridicidad, y esta de la culpabilidad, el tratamiento del error acerca de los presupuestos objetivos de la causa de justificación permite acoger soluciones que concebimos más coherentes y justas. Cabe, sin embargo, reconocer que la ubicación sistemática de este error ha suscitado mucha polémica ${ }^{47}$ y que, incluso entre los partidarios de la concepción personal del injusto y tripartita del delito, no se alcanzan las mismas soluciones, en virtud de las distintas vertientes de la teoría de la culpabilidad ${ }^{48}$.

En efecto, a partir de la teoría restringida de la culpabilidad, mayoritaria tanto

45 De esta forma manifiesta que "(s)i la suposición es objetivamente invencible determinará la impunidad, y si es objetivamente vencible, la aplicación de la imprudencia (art. 14,1 CP). Debe rechazarse la opinión contraria del finalismo (teoría estricta de la culpabilidad), que considera presente en estos casos un error de prohibición (como error de permisión). Sólo concurrirá un tal error de permisión cuando el sujeto crea erróneamente que le asiste una causa de justificación que en realidad el Derecho no admite, o cuando yerre sobre los límites normativos de una causa de justificación admitida legalmente" Mir Puig (2004), pp. 421-422, cursivas en el original. En el mismo sentido BaLdó LaviLLA (1994), pp. 126-127, según el cual "el que se representa subjetivamente de forma errónea un peligro ex ante objetivamente inexistente no quedará cubierto en su acción de salvaguarda propia o ajena por una verdadera causa de justificación de estado de necesidad, sino, en su caso -en función del grado de apariencia de peligro- por la regulación de las eximentes putativas -error- [...] su injerencia en esferas organizativas ajenas sólo posee el carácter de injerencia objetivamente típica -mas no subjetivamente típica-". De lo que concluye: "aquí entendemos que el estado de necesidad putativo no constituye una facultad justificante stricto sensu, sino una causa de exclusión de la imputación «subjetiva» del supuesto de hecho objetivamente prohibido -error de tipo «negativo»" Ibid., p. 139, cursivas en el original. En la misma línea de argumentos BaLdó LaviLLA (1994), pp. 267-270, 294-301, considera que el error sobre los presupuestos objetivos de la legítima defensa (legítima defensa putativa) debe ser tratado como error de tipo «negativo». En la línea de los planteamientos de Mir Puig también se manifiesta SiLVA SÁNCHEZ, Jesús-María. Aproximación al Derecho Penal contemporáneo. Montevideo-Buenos Aires: B de F, 2010, pp. 641 y ss.

46 Desde luego se llegaría a una solución materialmente más justa si MIR PUIG mantuviera aquí una propuesta similar a la de los casos de falta del elemento subjetivo de justificación, es decir, favorable a la graduación del injusto imprudente. De modo que en la conducta imprudente cometida en un estado de necesidad putativo o (de admitirse) en legítima defensa putativa, con error vencible en la valoración de la situación justificante, se pudiera graduar el injusto, beneficiándose de la atenuación de la pena, en el caso de que se estimara para estos supuestos la eximente incompleta (art. 21,1 en relación con el 68 CP 1995).

47 Como exponen Muñoz Conde (1989), pp. 21-92 y Roxin (1997), pp.459-471, 579-586, que analizan ampliamente la problemática de la delimitación entre error de tipo y de prohibición y puntualizan la dificultad que muchas veces representa identificar un tipo de error u otro cuando el error recae sobre un elemento normativo del tipo, o circunstancia del hecho que requiera un juicio de antijuridicidad, o sobre los presupuestos materiales de una causa de justificación, así como en los supuestos de leyes penales en blanco.

48 A este respeto véanse, Muñoz Conde (1989), pp. 25 y ss.; Roxin (1997), pp. 579-589; Trapero Barreales (2004), pp. 78 y ss., 139 y ss. 
en la doctrina alemana, como en la española ${ }^{49}$, se llega a resultados similares a los de la concepción bipartita del delito ${ }^{50}$. Para aquella, el dolo requiere "el conocimiento de las circunstancias del tipo legal" y además "la no suposición de circunstancias justificantes" ${ }^{51}$, y queda excluido en consecuencia tanto por la falta de conocimiento de los presupuestos del tipo legal, como por la suposición errónea de circunstancias objetivas de justificación. De modo que estas circunstancias relevantes del hecho son tratadas de igual forma y repercuten de igual modo en el tratamiento del error: "Quien yerra sobre una circunstancia de la que depende el injusto de su conducta no sabe lo que hace y obra sin dolo delictivo, porque aquello que se representa no merece desaprobación jurídica. Por el contrario, actúa en error de prohibición, quien sabe lo que hace, pero cree erróneamente que puede actuar así" ${ }^{52}$. Lo que desde luego nos da a entender que para Roxin, en casos peculiares como este, es necesario, para determinar el tipo de delito, que el dolo proyecte sus efectos no solo sobre los elementos objetivos del tipo, sino también sobre la ausencia de los elementos objetivos de las causas de justificación.

Roxin manifiesta que "(q)uien supone circunstancias cuya concurrencia justificaría el hecho actúa en razón de una finalidad que es completamente compatible con las normas del Derecho. Lo que pretende es jurídicamente intachable no sólo según su opinión subjetiva -no decisiva-, sino también según el juicio objetivo del legislador. [...] Actúa dolosamente quien se decide por una conducta que está prohibida por el ordenamiento jurídico (aun cuando no conozca esta prohibición). A quien sin embargo se guía por representaciones que también en un enjuiciamiento objetivo se dirigen a algo jurídicamente permitido, y produce un resultado indeseado por falta de atención y cuidado, le es aplicable el reproche de la imprudencia. Así sucede en el error sobre los presupuestos objetivos o materiales de una causa de justificación, que en consecuencia hay que equiparar a un error de tipo" 53 .

Todo lo cual lo lleva a concluir que "(q)uien hace algo injusto porque no ha examinado con suficiente cuidado la situación actúa siempre sólo imprudentemente y no es un sujeto doloso" "54. Lo que, según entendemos, no es la solución más coherente, al menos desde el punto de vista teórico, con la concepción tripartita del delito, porque para determinar el tipo de delito (si doloso o imprudente), termina por recurrir a elementos que ya no se encuentran en la tipicidad, sino que pertenecen a la antijuridicidad (presupuestos objetivos de la causa de justificación).

49 Confiera al respecto Díaz y García Conlledo (2008), pp. 170 y ss.

50 Con respecto, específicamente, a la similitud de los resultados alcanzados desde una concepción bipartita del delito y desde la teoría restringida de la culpabilidad, Roxin (1997), p. 586, manifiesta: "La teoría de los elementos negativos del tipo, al incluir los presupuestos de la justificación en el 'tipo legal' como circunstancias negativas, alcanza [...] el mismo resultado al que llega la teoría restringida de la culpabilidad".

51 Ídem.

52 Ídem.

53 Roxin (1997), pp. 583-584.

54 Roxin (1997), p. 585. 
Así, para Roxin, si en la legítima defensa putativa y en el estado de necesidad putativo el sujeto no actúa dentro de lo razonable y no aprecia la situación cuidadosamente dentro de los márgenes del riesgo permitido, la consideración errónea de la situación de peligro se debe a la imprudencia del sujeto y como tal responderá por el delito imprudente. No se apreciará la causa de justificación y el error vencible sobre los presupuestos de la causa de justificación tendrá el mismo efecto que el error de tipo vencible. Como consecuencia, la conducta imprudente realizada bajo la errónea percepción del presupuesto objetivo de una causa de justificación seguirá siendo calificada como imprudente, sin que el error vencible tenga efectos en la medición de la pena.

En contra de tales posturas, MuÑoz CondE apuntó, desde 1989, las consecuencias a que podía conducir la similitud de tratamiento entre el error de tipo y el error en los presupuestos objetivos de una causa de justificación. En efecto, no le parecía acertado convertir, desde la perspectiva de las consecuencias, una causa de exculpación en una auténtica causa de exclusión del injusto, eliminando tanto las posibilidades de que el afectado por la acción errónea pueda a la vez reaccionar de forma justificada en legítima defensa, como la responsabilidad civil directa del que actúa con error.

Según su postura, por tanto, el error invencible sobre los presupuestos de la causa de justificación no convierte la acción en una conducta lícita, ni el error vencible convierte la conducta en imprudente. Esta cuestión "no puede tratarse sistemáticamente en el ámbito del tipo de injusto, como error de tipo, sino en el ámbito de la culpabilidad, como error de prohibición [...]. Es decir, excluyendo la responsabilidad criminal (por falta de culpabilidad, que no de injusto), si es invencible, $o$ atenuando la pena $[\ldots]$ si es vencible" ${ }^{95}$.

La ventaja de este planteamiento, según manifiesta, se observa en la medida en que posibilita "un tratamiento conjunto de todos los errores posibles sobre las causas de justificación, bien sea sobre su existencia, sobre sus límites o sobre sus presupuestos, sin tener que realizar formalistas escisiones entre sus elementos, no siempre separables, complicando aún más la ya muy complicada teoría del error"56. De este modo, tanto el error sobre los presupuestos de la causa de justificación (causa de justificación putativa), como el error sobre su existencia o límites deben ser tratados en su opinión como error de prohibición, situándose su propuesta en el ámbito de la teoría estricta de la culpabilidad.

Actualmente MuÑoz CONDE y GarCía ArÁn, manteniendo en lo esencial la consideración de que las causas de justificación putativas afectan a la valoración de la culpabilidad, han introducido matices en la valoración de estos supuestos, a partir del criterio de lo «razonable» ${ }^{57}$.

\footnotetext{
55 Muñoz Conde (1989), p. 56.

56 Muñoz Conde (1989), pp. 56-57.

57 Muñoz Conde y García Arán (2010), pp. 314-316, 325, 329, 384-385. La adopción de este criterio ya había sido
} 
Se trata de un criterio objetivo, de origen jurisprudencial, que considera suficiente para la apreciación de la causa de justificación, la creencia razonable de la existencia ex ante del presupuesto objetivo de la situación justificante, aunque excepcionalmente ex post tal presupuesto no haya existido. La objetivación de la percepción subjetiva del individuo en estos casos puede ser alcanzada a partir de los criterios que estos autores utilizan para delimitar el tipo de injusto del delito imprudente y a través de los baremos de imputación objetiva (riesgo permitido, adecuación social, etc.). Así, “(q)uien actúa ex ante dentro de los márgenes admitidos socialmente al apreciar el presupuesto de una causa de justificación, actúa justificadamente, aunque luego ex post resulte que su percepción de la realidad fue objetivamente errónea. El verdadero error jurídicamente relevante comenzará a plantearse sólo cuando el sujeto traspase en su apreciación los límites del riesgo permitido y de lo razonable y adecuado socialmente. La repercusión práctica de lo que se acaba de decir se refleja sobre todo en que, mientras exista causa de justificación, no habrá responsabilidad de ningún tipo (ni penal, ni civil, ni administrativa) y tampoco cabe legítima defensa de la persona sobre la que recae la acción justificada, aunque sí el estado de necesidad, en la medida en que esta persona no haya provocado la suposición errónea del que actúa justificadamente" 58 .

Así, por ejemplo, en la legítima defensa putativa, cuando "el sujeto, dentro de los límites del riesgo permitido y de lo adecuado socialmente, crea razonablemente que va a ser víctima de una agresión" la conducta se justifica a pesar de que no se dé el presupuesto objetivo de la causa de justificación ${ }^{59}$. De constatarse que se trata de un error inevitable ex ante, es como si la agresión fuera

\footnotetext{
defendida por MUÑoz CONDE, Francisco. “¿«Legítima» defensa putativa? Un caso límite entre justificación y exculpación”. En: Schünemann, Bernd y De Figueiredo Dias, Jorge (Coords.). Fundamentos de un sistema europeo del Derecho penal. Libro-bomenaje a Claus Roxin. Barcelona: Bosch, 1995, pp. 192-199, en la valoración de la legítima defensa putativa. El actual desarrollo de su propuesta, desde una perspectiva comparada, puede verse en el artículo MuÑoz Conde, Francisco. "Un caso límite entre justificación y exculpación: la legítima defensa putativa". Yамамoto, María Verónica (Trad.). Revista Penal, $\mathrm{N}^{\mathrm{o}} 24,2009$, pp. 122 y ss.

58 Muñoz Conde y García Arán (2010), p. 314. Favorable a la exclusión de la antijuridicidad, aunque partiendo de la teoría restringida de la culpabilidad y de la teoría de los elementos negativos del tipo, LuZÓN PeÑa (2008), pp. 13-14, ejemplifica: "Error objetivamente inevitable sobre los presupuestos de la causa de justificación legítima defensa: unos jóvenes deciden gastarle una broma pesada a un compañero que trabaja en una joyería simulando un atraco, para lo cual uno de ellos entra con la cara parcialmente tapada a la joyería y amenaza con una pistola, que él sabe que lleva descargada, al empleado conminándole a que le entregue joyas valiosas pero pensando confesarle inmediatamente a continuación que era una broma, y el dueño, que lo ve desde la trastienda y tiene a su vez una pistola, creyendo razonablemente que es un atraco real y la pistola del atracador está cargada, le dispara alcanzándole en la mano con la que empuñaba el arma para desarmarlo y reducirlo. En esta defensa putativa se excluye la antijuridicidad (además del tipo subjetivo, el dolo y la imprudencia, para la teoría restringida de la culpabilidad, que comparto con un amplio sector), ya que con esa puesta en escena no era objetivamente previsible que fuera un atraco simulado y faltaran los presupuestos agresión ilegítima real y necesidad del medio y por tanto el joyero se representó fundada, razonablemente una situación de legítima defensa contra un agresor armado en la que era perfectamente lícito lesionarle de un disparo para desarmarle y que por ello no había ningún deber de evitar". Su postura, sin embargo, es más restrictiva a la hora de excluir la antijuridicidad con los efectos que la exclusión supone en los demás ámbitos del ordenamiento jurídico, en la medida en que la condiciona a que el error objetivamente inevitable no haya sido precedido por una conducta ilícita, o un ilícito administrativo. Requiere, por tanto, para la exclusión global de la antijuridicidad la valoración global de la conducta, lo que le conduce a admitir en determinados casos que la exclusión de la antijuridicidad penal no elimine la responsabilidad extrapenal, o la responsabilidad por un delito distinto en relación al ilícito precedente

59 Muñoz Conde y García Arán (2010), p. 325, cursivas en el original. Acerca del tratamiento de la legítima defensa putativa vid. ampliamente Muñoz Conde (1995), pp. 185-199; Muñoz Conde (2009), pp. 123 y ss..
} 
efectivamente real, una vez que ex ante se dan los requisitos de la eximente. Lo mismo puede decirse del estado de necesidad putativo ${ }^{60}$.

En este sentido, "la percepción errónea del presupuesto fáctico de la respectiva causa de justificación que se mantiene dentro del riesgo permitido razonable debe ser tratada igual que los casos de existencia real del mismo, en la medida en que cualquier persona en esa situación hubiera supuesto igualmente que, por ejemplo, iba a ser víctima de una agresión o que se daban los presupuestos del estado de necesidad (la existencia de un peligro). Los problemas que aquí se suscitan son similares a los que se dan cuando el hecho se produce por caso fortuito, no existiendo otra salida para el tercero inocente que es víctima del lamentable error que invocar el estado de necesidad. Ahora bien, si el error no cabe dentro del riesgo permitido razonable y se debe a miedo, precipitación, etc., el hecho será antijurídico y habrá que tratarlo por la vía del error de prohibición, probablemente vencible, o la del miedo insuperable" ${ }^{\text {. }}$.

En otras palabras, cuando el error se deba a una creencia puramente personal, es decir, cuando no se pueda reconocer ex ante de forma racional y fundada el presupuesto objetivo de la causa de justificación, este déficit personal pasará a ser valorado en el ámbito de la culpabilidad. Es decir, se mantiene la calificación de la conducta (dolosa o imprudente), y la errónea percepción del sujeto será tratada en el ámbito del error de prohibición, que podrá ser vencible o no, con arreglo a lo dispuesto en el art. 14.3 CP 1995, valorándose, incluso, la posibilidad de estimar una eximente de culpabilidad, dependiendo de cómo la "razonabilidad de la creencia de la persona en la presencia de un mal amenazante" afecte a la exigibilidad de actuar conforme a Derecho ${ }^{62}$.

El matiz introducido en la postura de MuÑoz Conde a partir del criterio de lo

60 Según manifiestan Muñoz Conde y García Arán (2010), p. 329, cursivas en el original: “debe considerarse que actúa justificadamente quien, apreciando la situación cuidadosamente y dentro de los márgenes del riesgo permitido, considera erróneamente que existe una situación de peligro que no se da realmente. Criterios objetivos y objetivables, como la diligencia debida, conductor experimentado, etc., pueden servir para delimitar los márgenes de error en la apreciación de la realidad que admite el estado de necesidad como causa de justificación, sin tener que recurrir a la exclusión de la culpabilidad por la vía del error indirecto de probibición". En contra, SAnz Morán, Ángel José. "Teoría general de la justificación". Revista Penal, $\mathrm{N}^{\circ}$ 5, 2000, p. 84, que adopta la solución del error de tipo. Una postura intermedia es la manifestada por Trapero Barreales, María A. "El examen conforme a deber: ¿especial elemento subjetivo de justificación?”. En: Quintero Olivares, Gonzalo y Morales Prats, Fermín (Coords.). El nuevo Derecho Penal español. Estudios penales en memoria del Profesor José Manuel Valle Muñiz, Navarra: Aranzadi, 2001, pp. 347 y ss., en la valoración del deber de examen como criterio de vencibilidad o invencibilidad del error. Por un lado se acerca a la postura de MuÑoz CONDE al defender la posibilidad de equiparación entre una causa de justificación putativa y una causa de justificación real, aunque matiza que esta equiparación es correcta siempre y cuando la causa de justificación putativa dé lugar a la apreciación, no de la eximente supuesta, sino del caso fortuito: “(c)cuando el sujeto, en cumplimiento de este deber de examen y comprobación, se comporta como lo hubiera hecho el hombre medio ideal colocado en su misma situación, cumple con las normas de cuidado exigibles objetivamente en esta actuación, o sea, de manera diligente y prudente, y por tanto su error sobre la concurrencia objetiva de justificación será valorado como objetivamente invencible y estaremos en presencia de una conducta justificada por la aplicación del caso fortuito" Trapero Barreales (2001), p. 862. Sin embargo, cuando el error sobre el presupuesto objetivo de la causa de justificación es vencible -con infracción del deber de examen ex ante- Ibíd., pp. 862-863, considera que la conducta debe ser valorada como imprudente, aplicando en este caso lo establecido para el error de tipo.

61 Muñoz Conde y García Arán (2010), p. 385, cursivas en el original.

62 Refiriéndose al criterio propuesto por VARONA GómEZ, Daniel. El miedo insuperable. Una reconstrucción de la eximente desde una teoría de la justicia. Granada: Comares, 2000, p. 197. 
razonable no significa, por tanto, la aceptación de la teoría restringida de la culpabilidad defendida mayoritariamente en la doctrina alemana y española, pues en ningún momento equipara, ni siquiera en cuanto a los efectos, el error en los presupuestos objetivos de las causas de justificación -ya sea vencible o no- al error de tipo. Lo que, según consideramos, representa una solución más coherente con la concepción tripartita del delito, porque no hace falta recurrir, para determinar el tipo de delito (si doloso o imprudente), a la valoración de elementos que pertenecen a la antijuridicidad ni siquiera en este caso peculiar de error sobre los presupuestos objetivos de una causa de justificación.

La propuesta de MuÑoz Conde, representa una medida que permite la atenuación de la pena cuando se trata de un error vencible, operando efectos en el ámbito de la culpabilidad, pero no en virtud de circunstancias que afectan a la antijuridicidad. En lo que tiene razón, pues en los casos de causas de justificación putativas realmente no existe el presupuesto que abre paso a la autorización de la conducta típica, y por lo tanto no se puede hablar con propiedad en esta clase de error de graduación del injusto. Solamente cuando, de un modo excepcional, se caracterice la razonabilidad del error invencible acerca de la existencia del mal amenazante será posible mantener el tratamiento del error sobre los presupuestos en el campo de la justificación, en sede de injusto, pero como el propio MuÑoz CONDE aclara, esta circunstancia no existe cuando de lo que se trata es de valorar la repercusión de un error personal que conduce a la valoración de una eximente putativa.

La antijuridicidad de la conducta realizada bajo un error personal vencible o invencible sobre el presupuesto objetivo de la causa de justificación no se ve, por tanto, afectada y este error solo será apreciado, así como el error sobre los límites de la causa de justificación o sobre la existencia de la causa de justificación misma, como error de prohibición, en el ámbito de la culpabilidad.

La consideración de estos casos en el ámbito de la culpabilidad podría asimismo dar lugar a una solución, no a través de la vía del error, sino a partir de la valoración de una eximente de la culpabilidad (completa o incompleta), como puede ser el caso de la eximente de miedo insuperable (art. 20.6 CP 1995), cuando el error acerca de la existencia del mal amenazante -que impide apreciar el estado de necesidad (justificante)- es el motivo desencadenante del miedo ${ }^{63}$.

Resumiendo, como se ha podido observar, aunque se parta de la adopción de la concepción personal del injusto y tripartita del delito, también para los delitos imprudentes, capaz de respetar la autonomía entre tipo y antijuridicidad, entre antijuridicidad y culpabilidad, así como entre error de tipo y de prohibición, con consecuencias en la punibilidad, ello no ha sido suficiente para alcanzar

63 Cuerda Arnau, María Luisa. El miedo insuperable. Su delimitación frente al estado de necesidad. Valencia: Tirant lo Blanch, 1997, pp. 123-128; VArona Gómez (2000), pp. 188-198. 
un punto de encuentro en el tratamiento del error en los presupuestos objetivos de las causas de justificación, con una evidente repercusión en el alcance de la imprudencia y su punibilidad.

En efecto, de equiparar el tratamiento del error vencible acerca de los presupuestos objetivos de la causa de justificación al error de tipo, la valoración de la conducta imprudente del sujeto que se ve inmerso en este error no se beneficia de ningún tipo de atenuación. Mientras que si se traslada la valoración de este error al ámbito de la culpabilidad (según lo establecido para el error de prohibición, o, de aplicarse una eximente de la culpabilidad, si se dan sus requisitos), la conducta sigue siendo la misma (dolosa o imprudente), con la diferencia de que se beneficia de la atenuación de la pena, según lo establecido respectivamente en el art. 14.3 CP 1995 (para la solución del error de prohibición vencible), o según lo previsto en el art. 21.1 en relación al art. 68 CP 1995 (para la solución de la graduación de la culpabilidad -si se aprecia la eximente incompleta de miedo insuperable-).

Por lo que cabe preguntarse, qué postura es la más adecuada.

\section{Hacia unA DElimitación DEL INJUSTO IMPRUdente COHE- RENTE CON LA CONCEPCIÓN TRIPARTITA DEL DELITO}

De cara a los lindes de este trabajo, no descenderemos al análisis específico de la problemática del error en Derecho Penal, sino que nos limitaremos a valorar la trascendencia de las dos cuestiones planteadas para la caracterización y punibilidad del delito imprudente.

Respecto de la valoración del elemento subjetivo de justificación, partimos de una concepción personal del injusto y tripartita del delito. Además, consideramos que solo tiene sentido referirse a la existencia de un elemento subjetivo de justificación -del mismo modo que en la tipicidad, pero sin confundirse con el elemento subjetivo de la tipicidad-, en la medida en que se configure desde la perspectiva ex ante. Es decir, verificando en el caso concreto que el sujeto tenía acceso a las circunstancias que caracterizaban la situación justificante y que actuó en base a ello. No siendo suficiente para considerar la conducta justificada que esta coincida casualmente con los requisitos objetivos de una causa de justificación, sino que, además, debe reflejar la percepción de estos elementos, porque estaban al alcance del sujeto en el momento de la acción ${ }^{64}$.

\footnotetext{
64 Esta postura objetivable del elemento subjetivo de la justificación desde la perspectiva ex ante, además de evitar la confusión entre antijuridicidad y culpabilidad, permite valorar con mayor claridad y menos contradicciones sistemáticas el tratamiento del error sobre los presupuestos objetivos de las causas de justificación, en la línea de la propuesta de MuÑoz Conde y García ArÁn (2010), pp. 314-316, 325, 329, 384-385.
} 
Con esta base, entendemos por un lado que no se confunde el elemento subjetivo del tipo - que condiciona la configuración de un determinado tipo de delito como doloso o imprudente- con el elemento subjetivo de la antijuridicidad, puesto que se proyectan sobre elementos objetivos distintos. La valoración de la ausencia o presencia del elemento subjetivo de una causa de justificación no se confunde con la conciencia misma de actuar lícita o ilícitamente, que es un juicio de valor realizado a posteriori -en sede de culpabilidad- una vez que el sujeto tiene a su alcance las circunstancias del hecho. Pues, como afirma RoxIN, "cuando alguien no tiene la posibilidad de acceder al conocimiento del injusto, no es accesible para el mandato de la norma" ${ }^{65}$. Y, efectivamente, pertenece a la culpabilidad, en la medida en que la afirmación de la conciencia de la antijuridicidad depende de la previa constatación de que estamos ante un sujeto capaz de actuar motivadamente ${ }^{66}$. Con lo cual, deducimos, es posible conciliar la concepción personal del injusto y tripartita del delito también para los delitos imprudentes, admitiendo la existencia de un elemento subjetivo tanto en la tipicidad como en las causas de justificación, sin que ello suponga la confusión o unión de las categorías sistemáticas de la tipicidad y de la antijuridicidad, que son diferenciables entre sí y, también, con respecto a la culpabilidad y sus elementos.

Por otro lado, entendemos que quien realiza objetivamente una conducta correcta, sin el conocimiento de la situación justificante, sigue actuando en contrariedad a Derecho, y por tanto el desvalor de acción persiste. Así, la conducta imprudente que produce un resultado lesivo que coincide casualmente con una conducta objetiva de salvaguarda del bien jurídico de un tercero, no adquiere el sentido de justificada y por lo tanto sigue siendo desvalorada, si el autor no era en absoluto consciente de ello. Cabe, sin embargo, reconocer el valor objetivo de la existencia de la situación justificante, que no puede ser dejada al margen de la valoración del suceso global en la medida en que representa un evidente valor positivo en el análisis de distribución de cargas. Los efectos que produce pueden en esta línea variar según se opte, por ejemplo, por la solución de la tentativa imprudente (impune) o por la aplicación de la eximente incompleta (al menos en España, con arreglo al art. 21.1 en relación al art. 68 CP 1995), con una clara repercusión en los límites de la punibilidad del hecho imprudente en sí mismo considerado. Al respecto, por los efectos sistemáticos que produce, consideramos más adecuada la propuesta de Mir PUIG de estimar la eximente incompleta, viabilizando en sede de imprudencia la graduación del injusto con la consecuente atenuación de la pena con arreglo al art. 21.1 en relación con el art. 68 CP 1995.

65 Roxin (1997), p. 878.

66 En efecto, si no realizamos esta diferenciación entre elemento subjetivo de justificación -que se limita al conocimiento de las circunstancias objetivas que caracterizan la situación justificante y la dirección de la conducta hacia la salvaguarda de un interés- y conciencia de la antijuridicidad -elemento de la culpabilidad-, resultaría extremadamente difícil aceptar que quien sufre una alteración psíquica grave puede actuar en legítima defensa. 
La repercusión de esa postura puede verse, por ejemplo, cuando de la intervención de distintos sujetos en el delito. En efecto, cuando se trata de valorar la conducta de los sujetos que intervienen en una conducta objetivamente justificada, teniendo como referente la legislación penal española, si adoptáramos para la conducta principal imprudente -objetivamente justificada, realizada sin el conocimiento de los elementos objetivos de la causa de justificación- la solución de la tentativa, los intervinientes en el hecho imprudente solo podrían ser de alguna forma castigados si actuaran de forma dolosa y en concepto de autor. Pues, siendo la tentativa imprudente atípica, no serían punibles los demás intervinientes imprudentes en ella, ni tampoco el partícipe doloso, como consecuencia del principio de accesoriedad limitada de la participación.

$\mathrm{Si}$, por el contrario, se estima para el mismo supuesto la eximente incompleta (hecho principal imprudente, pero con la pena atenuada), se ajustan de manera más adecuada las fronteras de la punibilidad. De manera que la adopción de esta segunda solución puede ser valorada incluso como beneficiosa, en la medida en que evita lagunas de punibilidad en el ámbito de la imprudencia. Aunque para lograr este efecto beneficioso se hace necesario marcar los contornos de la autoría respecto de la participación.

Por su parte, en cuanto al problema contrario, esto es, respecto de los casos de error en los presupuestos objetivos de la causa de justificación, hemos visto que la suposición objetivamente invencible de sus presupuestos es tratada mayoritariamente -aunque en base a fundamentos distintos- como error de tipo. Mientras que un sector minoritario defiende la solución del error de prohibición, aunque excepcionalmente, de darse la constatación ex ante razonable de los presupuestos de la causa de justificación, se admite dar lugar a la justificación, como si la situación justificante fuera real, y, como tal, se entienda que el que se encuentre inmerso en esta clase de error no actúa de forma antijurídica. De manera que para el sector minoritario el error en la percepción de la situación justificante deberá ser valorado, como regla general, en la culpabilidad como error de prohibición ${ }^{67}$, pudiendo darse la posibilidad de apreciar, también en sede de culpabilidad, la eximente (normalmente incompleta) de miedo insuperable si se dan sus presupuestos ${ }^{68}$.

Como hemos indicado, consideramos más adecuado, en coherencia con la concepción tripartita del delito, que la valoración de los presupuestos objetivos de la antijuridicidad no repercutan en la tipicidad y que, por lo tanto, no afecte a la calificación del tipo de delito (si doloso o imprudente), ni repercutan, como regla general, en la graduación del injusto (aunque excepcionalmente pueda dar-

67 Muñoz Conde y García Arán (2010), pp. 384-385.

68 Es decir, si la suposición del mal amenazante desencadena un cuadro de miedo insuperable, según CuERDA ARNAU (1997), pp. 123-128; VArona Gómez (2000), pp. 188-198. Esta solución también es aceptada por MuÑoz Conde y García ArÁN (2010), p. 385. 
se el caso de que la causa de justificación putativa pueda ser aceptada desde la perspectiva ex ante como si fuera real), por lo que, en consecuencia, en nuestra opinión, la propuesta más adecuada es la del sector minoritario - encabezada por MuÑOZ CONDE y GARCÍA ARÁN- acerca de la valoración de los presupuestos objetivos de una causa de justificación.

¿Qué consecuencias tiene el adoptar esta solución en la delimitación del injusto imprudente y su punibilidad?

En la hipótesis de invencibilidad del error en la percepción de los presupuestos de la causa de justificación, la solución del error de prohibición conduce a que no se vean afectadas ni la tipicidad ni la antijuridicidad de la conducta imprudente, repercutiendo el error en la culpabilidad ${ }^{69}$. Lo que, además de la evidente caracterización del injusto, implica que el autor de la conducta realizada bajo error de prohibición deberá resarcir los daños y perjuicios causados a la víctima (cabe responsabilidad civil), y que esta podrá reaccionar justificadamente en legítima defensa frente a aquella. Asimismo, esta solución permite una delimitación más adecuada de la punibilidad, porque sigue existiendo una conducta típica y antijurídica en la que participar, lo que puede ser valorado incluso como beneficioso, en la medida en que evita lagunas de punibilidad en el ámbito de la imprudencia. Aunque cabe matizar que este efecto beneficioso depende de que estén claramente delimitados los contornos de la autoría respecto de la participación ${ }^{70}$.

En los casos de vencibilidad del error sobre los presupuestos objetivos de una causa de justificación, la solución del error de prohibición presenta la ventaja, como hemos indicado antes, de permitir la atenuación de la pena del delito imprudente en base al artículo 14.3 CP 1995. Es decir, en términos prácticos, se admite que la conducta imprudente pueda ser beneficiada con la atenuación de la pena, como consecuencia del tratamiento del error sobre los presupuestos objetivos de una causa de justificación como error de prohibición ${ }^{71}$. Pudiendo, incluso, valorarse, en el caso específico de que el error motive al sujeto a actuar impulsado por el miedo -manteniendo la solución en el ámbito de la culpabilidad-, el aplicar la eximente de miedo insuperable (art. 20.6 CP 1995), completa o incompleta, dependiendo del carácter razonable de la creencia en la existencia del $\mathrm{mal}^{72}$.

\footnotetext{
69 En este sentido también se manifiesta Romeo Casabona, Carlos María. Conducta peligrosa e imprudencia en la sociedad de riesgo. Granada: Comares, 2005, pp. 60-61.

70 Todas estas posibilidades resultarían descartadas si se equiparase el tratamiento de estos supuestos al error de tipo (negativo), pues en la hipótesis de invencibilidad del error se eliminaría ya la propia tipicidad.

71 Mientras que desde el sector que coincide en equiparar el tratamiento de estos casos al del error de tipo (negativo), el error vencible conduciría a que no cambiase la valoración del hecho imprudente y, en la práctica, no fuera beneficiado por la atenuación obligatoria de la pena. Por ejemplo, cuando el sujeto realiza un tipo imprudente para prestar auxilio a un tercero que supone (inmerso en error vencible) estar herido grave.

72 En esta línea nos posicionamos a favor de Cuerda Arnau (1997), pp. 123-128 y, especialmente, Varona Gómez (2000), pp. 188-198.
} 
Así, como se observa, la valoración del error tiene consecuencias en la delimitación del injusto imprudente, su punibilidad y también en la medición de la pena. Lo que significa que también puede afectar a la valoración de las conductas de los demás intervinientes en un hecho principal imprudente realizado bajo la errónea representación del presupuesto objetivo de una causa de justificación, pudiendo apreciarse distintas soluciones dependiendo del punto de partida en el tratamiento del error.

Si se opta, como nosotros, por las soluciones en el ámbito de la culpabilidad -a través del error de prohibición y, en su caso, de la eximente de miedo insuperable-, será necesario en estos casos para la valoración de la intervención de otras personas marcar los contornos de la autoría y, si se adopta la accesoriedad limitada de la participación, los límites de la autoría respecto de la participación.

Por último, y de un modo general, consideramos importante recalcar que, si se adopta para los delitos imprudentes la concepción tripartita de delito en los términos que acabamos de esbozar, es posible mantener un análisis escalonado de las categorías sistemáticas del delito, de forma equilibrada y similar, tanto en los delitos dolosos como en los imprudentes, de manera que ya en este aspecto el delito imprudente no demanda un tratamiento globalmente diferenciado o específico en comparación a los delitos dolosos. 


\section{Bibliografía}

Alonso Álamo, Mercedes. "La acción «libera in causa»". Anuario de Derecho Penal y Ciencias Penales, № 42, 1989, pp. 55-107.

Baldó Lavilla, Francisco. Estado de necesidad y legitima defensa: un estudio sobre las «situaciones de necesidad». Barcelona: J. M. Bosch Editor, 1994.

Carbonell Mateu, Juan Carlos. "El sistema de justificación en el art. 20 CP/1995". En: Quintero Olivares, Gonzalo y Morales Prats, Fermín (Coords.). El nuevo Derecho penal. Estudios penales en memoria del Profesor José Manuel Valle Muñiz. Navarra: Aranzadi, 2001, pp. 121141.

Corcoy Bidasolo, Mirentxu. El delito imprudente. Criterios de imputación del resultado. Montevideo-Buenos Aires: B de F, 2005.

Cuello Contreras, Joaquín. "Elemento objetivo y subjetivo de las causas de justificación". En: Quintero Olivares, Gonzalo y Morales Prats, Fermín (Coords.). El nuevo Derecho penal. Estudios penales en memoria del Profesor José Manuel Valle Muñiz. Navarra: Aranzadi, 2001, pp. 147-159.

Cuerda Arnau, María Luisa. El miedo insuperable. Su delimitación frente al estado de necesidad. Valencia: Tirant lo Blanch, 1997.

Díaz y García Conlledo, Miguel. El error sobre elementos normativos del tipo penal. Madrid: La Ley, 2008.

Díaz Pita, María del Mar. El dolo eventual. Valencia: Tirant lo Blanch, 1994.

DíEz Ripollés, José Luis. "La categoría de la antijuridicidad en Derecho Penal". En: Luzón Peña, Diego-Manuel y Mir Puig, Santiago (Coords.), Causas de justificación y de atipicidad en Derecho Penal. Navarra: Aranzadi, 1995, pp. 87-170.

Feijoo SÁnchez, Bernardo José. Resultado lesivo e imprudencia. Estudio sobre los límites de la responsabilidad penal por imprudencia y el criterio del «fin de protección de la norma de cuidado». Barcelona: J.M. Bosch, 2001.

GÜNTHER, Hans Ludwig. "La clasificación de las causas de justificación en Derecho Penal". En: Luzón Peña, Diego-Manuel y Mir Puig, Santiago (Coords.). LuZón PeÑa, Diego-Manuel (Trad.). Causas de justificación y de atipicidad en Derecho Penal, Navarra: Aranzadi, 1995, pp. 45-66.

Jakobs, Günther. Derecho Penal, Parte General. Fundamentos y teoría de la imputación. Cuello Contreras, Joaquín y Serrano GonzÁlez de Murillo, José Luis (Trads.). 2a Edición. Madrid: Marcial Pons, 1997.

Jescheck, Hans-Heinrich y Weigend, Thomas. Tratado de Derecho Penal: Parte General. Olmedo CARdenete, Miguel (Trad.). $5^{\text {a }}$ Edición. Granada: Comares, 2002.

LuZÓn Peña, Diego-Manuel. "Causas de atipicidad y causas de justificación". En: Luzón Peña, Diego-Manuel y Mir Puig, Santiago (Coords.). Causas 
de justificación y de atipicidad en Derecho Penal. Navarra: Aranzadi, 1995, pp. 21-43.

LuZón PeÑA, Diego-Manuel. Curso de Derecho Penal. Parte General I. Madrid: Editorial Universitas S.A., 1996.

Luzón PeÑA, Diego-Manuel. "Caso fortuito y creencia razonable: error objetivamente invencible y consentimiento presunto, como causas de justificación o de exclusión de la tipicidad penal". Revista General de Derecho Penal, No 9, 2008, pp. 2-34.

Mir Puig, Santiago. "Adiciones de Derecho español al $\S 31$ ". En Jescheck, Hans Heinrich. Tratado de Derecho Penal. Parte General. Volumen 1. Traducción y adiciones de Derecho español por Mir Puig, Santiago y Muñoz Conde, Francisco. Barcelona: Bosch, 1981.

Mir Puig, Santiago. Derecho Penal: Parte General. $7^{\text {a }}$ Edición. Barcelona: Reppertor, 2004.

Muñoz Conde, Francisco. El error en Derecho Penal. Valencia: Tirant lo Blanch, 1989.

MuÑoz Conde, Francisco. “¿«Legítima» defensa putativa? Un caso límite entre justificación y exculpación”. En: Schünemann, Bernd y De Figueiredo Dias, Jorge (Coords.). Fundamentos de un sistema europeo del Derecho penal. Libro-homenaje a Claus Roxin. Barcelona: Bosch, 1995, pp. 183-199.

MuÑoz Conde, Francisco. "Un caso límite entre justificación y exculpación: la legítima defensa putativa". Yамамото, María Verónica (Trad.). Revista Penal, No 24, 2009, pp. 122-134.

Muñoz Conde, Francisco y García Arán, Mercedes. Derecho Penal: Parte General. 8a Edición. Valencia: Tirant lo Blanch, 2010.

Pomares Cintas, Esther. La relevancia de las causas de justificación en los delitos imprudentes. Granada: Comares, 2004.

Romeo Casabona, Carlos María. Conducta peligrosa e imprudencia en la sociedad de riesgo. Granada: Comares, 2005.

Roxin, Claus. Derecho Penal. Parte General. Tomo I. Fundamentos de la teoría del delito. Luzón Peña, Diego-Manuel; Díaz y García Conlledo, Miguel y de Vicente Remesal, Javier (Trads.). Madrid: Civitas, 1997.

SAnz MorÁn, Ángel José. "Teoría general de la justificación”. Revista Penal, $\mathrm{N}^{\mathrm{o}}$ 5, 2000, pp. 74-89.

SAnz Morán, Ángel José. "Los elementos subjetivos de justificación”. En: Quintero Olivares, Gonzalo y Morales Prats, Fermín (Coords.). El nuevo Derecho Penal. Estudios penales en memoria del Profesor José Manuel Valle Muñiz. Navarra: Aranzadi, 2001, pp. 723-745.

SchünEmann, Bernd. "La función de la delimitación de injusto y culpabilidad". En: Schünemann, Bernd y De Figueiredo Dias, Jorge (Coords.). Fundamentos de un sistema europeo del Derecho Penal. LibroHomenaje a Claus Roxin. Barcelona: J. M. Bosch, 1995, pp. 205-245.

Silva SÁnchez, Jesús-María. Aproximación al Derecho Penal contemporáneo. Montevideo-Buenos Aires: B de F, 2010. 
Trapero Barreales, María A. Los elementos subjetivos en las causas de justificación y de atipicidad penal. Granada: Comares, 2000.

Trapero Barreales, María A. "El examen conforme a deber: ¿especial elemento subjetivo de justificación?". En: Quintero Olivares, Gonzalo y Morales Prats, Fermín (Coords.). El nuevo Derecho Penal español. Estudios penales en memoria del Profesor José Manuel Valle Muñiz. Navarra: Aranzadi, 2001, pp. 827-864.

Trapero Barreales, María A. El error en las causas de justificación. Valencia: Tirant lo Blanch, 2004.

VArona Gómez, Daniel. El miedo insuperable. Una reconstrucción de la eximente desde una teoría de la justicia. Granada: Comares, 2000.

VAlle MuÑIz, José Manuel. "Fundamento, alcance y función de las causas de justificación incompletas en el Código penal español". Anuario de Derecho Penal y Ciencias Penales, № 40, 1992, pp. 561-612.

Valle MuÑIz, José Manuel. "La naturaleza graduable de lo injusto y la actuación en desconocimiento del presupuesto objetivo de una causa de justificación". En: SiLva SÁnchez, Jesús María (Ed.). Política criminal y nuevo Derecho Penal. Libro homenaje a Claus Roxin. Barcelona: Bosch, 1997, pp. 439-467.

\section{Normas}

Código Penal Español 1973

Código Penal Español 1995 